\title{
El Coletivo: Un colectivo feminista de salud y sexualidad femenina en Brasil
}

Margarita Diaz

Debbie Rogow

Jose Barzelatto

Follow this and additional works at: https://knowledgecommons.popcouncil.org/departments_sbsr-pgy

Part of the Family, Life Course, and Society Commons, International Public Health Commons, Public Health Education and Promotion Commons, and the Women's Health Commons How does access to this work benefit you? Let us know!

\section{Recommended Citation}

Diaz, Margarita, Debbie Rogow, and Jose Barzelatto. 1995. "El Coletivo: Un colectivo feminista de salud y sexualidad femenina en Brasil," Quality/Calidad/Qualité no. 6. New York: Population Council. 
Calidad/Quality/Qualité, una publicación del Population Council, resalta ejemplos de programas de planificación familiar y salud reproductiva que se esmeran por dar servicios de alta calidad. Esta serie es parte del Programa Robert H. Ebert en Temas Críticos en Salud Reproductiva y Población, el cual, mediante esfuerzos científicos y prácticos, busca mejorar y expandir el alcance y la calidad de los servicios en salud reproductiva. Los fundamentos filosóficos del programa y de esta serie, parten de que las mujeres y sus parejas tienen derecho a recibir de los proveedores de servicios de salud reproductiva un trato respetuoso, información, continuidad en la atención y la presentación de opciones para elegir un método anticonceptivo. Los folletos reflejan uno de estos elementos necesarios para mejorar la calidad de los programas de planificación familiar.

Los proyectos para la documentación de la serie Calidad/Quality/Qualité los selecciona un Comité Asesor integrado por personas con una amplia experiencia en el campo de la salud reproductiva y comprometidas con el mejoramiento de la calidad de atención de los servicios. Estos proyectos muestran avances importantes en uno o más de los siguientes aspectos: ampliar la variedad de métodos anticonceptivos y tecnologías disponibles; suministrar la información que los clientes necesitan para tomar decisiones informadas sobre el manejo de su propia salud; reforzar la calidad de la interacción cliente/ proveedor y favorecer el contacto constante entre proveedores y clientes; ensayar estrategias innovadoras para mejorar la capacidad gerencial de los directivos y las habilidades técnicas de los proveedores de servicios de diferentes niveles de atención; expandir la gama de servicios y la información suministrada más allá de lo que usualmente se llama "planificación familiar"; y proporcionar atención en salud reproductiva a grupos desfavorecidos y sin acceso a los servicios.

Ninguno de los proyectos documentados en estas series se ofrece como un modelo para replicar. Por el contrario, cada uno está presentado como un ejemplo creativo inusual de valores, objetivos e implementación. Las "experiencias de aprendizaje" demuestran la actitud de autocrítica que se requiere para anticipar las necesidades de servicios de los clientes y encontrar los medios para satisfacerlas con los recursos existentes. Esta postura reflexiva se ejemplifica mediante la voluntad de responder tanto a cambios de las necesidades de los clientes como de transformaciones sociales y económicas más amplias que afectan a las sociedades. Creemos que documentar las decisiones cruciales que estos programas han tomado ayudará a reforzar la creencia de que la satisfacción personal con los servicios de salud reproductiva, está íntimamente ligada con el cumplimento de metas sociales más amplias en salud y población.

La publicación de la edición original en inglés de Calidad/Quality/Qualité fue posible gracias al apoyo de la Fundación Ford, la Fundación John D. y Catherine T. MacArthur y el Fondo de las Naciones Unidas para Actividades de Población (FNUAP).

La edición en español fue financiada por el proyecto INOPAL III (Investigación Operativa y Asistencia Técnica en Planificación Familiar y Salud Reproductiva en América Latina y el Caribe) que a su vez es financiado por la Agencia Internacional para el Desarrollo de los Estados Unidos (USAID) mediante el contrato No. CCP-95-C-00-00007-00.

Traducción al español:

Responsable de la publicación:
Carmen Fuertes

Silvia Llaguno

Número Seis 1995 ISSN 0-8734-057-2 Copyright The Population Council 1995 


\title{
El Coletivo: Un Colectivo Feminista de Salud y Sexualidad Femenina en Brasil
}

\author{
Por Margarita Díaz y Debbie Rogow \\ Introducción por José Barzelatto
}

\section{Introducción}

En el pasado, los programas de planificación familiar estaban diseñados principalmente para reducir el crecimiento excesivo de la población, haciendo a las mujeres objeto de políticas médicas y programas preparados para regular la fecundidad. Los resultados eran aproximaciones programáticas verticales que detenían el desarrollo de servicios completos. Este enfoque era guiado por una "perspectiva de enfermedad" resultado natural del exitoso récord de la medicina para encontrar "soluciones técnicas" orientadas a resolver problemas biológicos. Es este acercamiento biomédico a la fecundidad, combinado con los mitos culturales y los tabúes, lo que ha impedido que los programas de población traten adecuadamente los temas sexuales y de género. Sorprendentemente, aunque la sexualidad se encontraba en el centro de la vida reproductiva, hasta que surgió el SIDA, los programas de planificación familiar operaban bastante bien sin siquiera mencionar la palabra sexo.

Sin embargo, como lo atestigua el Plan de Acción, adoptado en 1994 en la Conferencia Mundial de Población de El Cairo, el estudio de la población ha empezado a cambiar su objetivo de "explosión demográfica" a salud sexual y reproductiva de cada ciudadano. Existe un número importante de factores detrás de este cambio. Uno de ellos es la reciente tendencia global a fortalecer a la sociedad civil. Ha habido un resurgimiento de movimientos democráticos y un incremento en la participación de agentes no gubernamentales en el desarrollo de políticas nacionales e internacionales. Otro factor ha sido la creciente aceptación de que la salud sexual y reproductiva es un bien social importante que vale la pena buscar sin importar las circunstancias demográficas.

Sin embargo, el más importante se refiere a las cambiantes necesidades y oportunidades para las mujeres. En el pasado, la elevada mortalidad y la imposibilidad de la mujer para regular su fecundidad contribuyeron a definir claramente roles de género: ellas reproducían y los hombres producían; el hecho de que tengamos sociedades patriarcales no es accidental. Pero la disminución en las tasas de mortalidad y el incremento en el control de la fecundidad han llevado a cambios en el equilibrio entre reproducción y sexualidad en las relaciones interpersonales. Ahora tener hijos puede ser un acuerdo con los deseos y decisiones de una pareja y las mujeres pueden convertirse en socias igualitarias al hombre en todos los aspectos de la vida.

Esta transición de roles sexuales y de género, y las responsabilidades que conlleva, tendrá un efecto mucho más importante en la humanidad del que tendrá la transición demográfica. Al concentrarse en el crecimiento poblacional, el campo de estudio de la población se ha enfocado en un problema muy importante, pero pasajero. Las transiciones demográficas se han realizado en periodos de veinte a cien años, dependiendo de la existencia o no de programas de planificación familiar efectivos, pero hubieran sucedido de todas maneras, aunque con diferentes costos sociales. Los cambios en el equilibrio de los papeles y el poder entre el hombre y la mujer son menos predecibles y más cruciales. Estamos empezando a comprender sus consecuencias y qué tan profundamente puede verse influenciada la sociedad por ellos. 
El movimiento feminista ha sido el responsable principal de plantear todos estos temas en la arena pública: Actualmente, las organizaciones femeninas están trabajando para contraatacar la sobremedicalización de los temas sexuales y reproductivos; para darles poder a las comunidades, particularmente a las mujeres, para redefinir los roles de género y las responsabilidades, así como para promover un diálogo público informado sobre estos temas. Es por este papel crucial que ellas tienen, que la Fundación Ford patrocina varios movimientos por la salud de las mujeres alrededor del mundo.

Mientras estos asuntos son la preocupación central en todos lados, el movimiento por la salud de las mujeres en América Latina ha tratado los temas de sexualidad y relaciones humanas de una manera probablemente más dinámica que en otras partes del mundo. Es así como nosotros dirigimos la mirada hacia esta región, buscando ideas de cómo establecer un acercamiento reproductivo y sexual. Esto es particularmente apropiado en relación con varios temas que han preocupado al campo de la planificación familiar por mucho tiempo, como la calidad de la atención, el diseño de un servicio integrado, así como la capacitación y motivación de quien lo provee.

El movimiento feminista nos ha mostrado que es posible traducir en servicios una aproximación a la salud reproductiva y sexual, y que esto puede hacerse aun con recursos muy limitados, tal como lo ha hecho el Colectivo Feminista Sexualidad y Salud en Sao Paulo, Brasil. Los servicios que ofrece el Coletivo demuestran que es más eficiente tener clientes satisfechas que usen apropiadamente los métodos anticonceptivos, y no sólo distribuirlos sin tener en cuenta qué hace la gente con ellos.

Esto resalta dos puntos importantes: la motivación del proveedor y la relación cliente-proveedor. No es una sorpresa que cuando los proveedores se sienten explotados y mal pagados, no tratan bien a sus clientes. La mayor parte de la insatisfacción del cliente se debe, de hecho, a la mala calidad de su encuentro con un proveedor. El Coletivo nos enseña la importancia de la relación cliente-proveedor y nos recuerda que debemos ofrecer al equipo de trabajo de la clínica una experiencia llena de sentido y un salario razonable para mejorar su situación en la vida. En el Coletivo, el equipo de trabajo se siente personal y profesionalmente beneficiado con su trabajo y eso se refleja en la calidad de los servicios que prestan.

En muchas clínicas de planificación familiar, la unidad estándar de evaluación -en realidad, el único dato fácilmente disponible- es el número de anticonceptivos distribuido o el número de clientes que ha sido atendido. Pero, si uno hace una verdadera evaluación de las necesidades de las clientes y trata de satisfacerlas, resulta evidente que los servicios de buena calidad no sólo ofrecen resultados positivos desde el punto de vista reproductivo y de salud sexual, sino también desde una perspectiva demográfica. En el caso del Coletivo, aunque no todas las mujeres que acuden a la clínica salen con un anticonceptivo (tal vez porque no lo desean en ese momento o porque tienen una infección), ellas se llevan la impresión de que hay alguien interesado en su bienestar. De esta manera, probablemente ellas regresen a solicitar otros servicios, quizá métodos anticonceptivos. Además, es más probable que las mujeres que salen del Coletivo usen de manera efectiva el método anticonceptivo que escogieron o, si sienten la necesidad, regresen por un método alternativo, que aquellas que acuden a las clínicas convencionales de planificación familiar. Esto ilustra claramente la necesidad de ir más allá de simplemente entrenar a proveedores para que distribuyan una variedad de métodos anticonceptivos.

Lo que hace la aproximación de salud reproductiva y sexual es situar a la sexualidad en el centro de la vida reproductiva. Retando lo que la medicina y la planificación familiar han hecho y haciendo una llamada hacia un trato más humanista y holístico de la salud. No es suficiente que el médico o el proveedor de planificación familiar diagnostique lo que está mal en el cuerpo de la mujer o decida cuál anticonceptivo sería mejor para ella. Los seres humanos somos más que biología, y observando cuidadosamente los problemas, no es posible tratar la anticoncepción como un tema independiente. Es necesario escuchar lo que la gente -en particular las mujeres- tiene que decir acerca de sus necesidades físicas, mentales y sociales, y entonces tratar de satisfacer esas demandas.

Durante la última década, el movimiento por la salud de las mujeres y el campo de estudios de población han empezado a establecer un diálogo significativo. A pesar de los riesgos de establecer un compromiso, que ambas partes perciben, estas conversaciones han sido cruciales mientras trabajan hacia una agenda más amplia sobre salud reproductiva y sexual. Irónicamente, este proceso no es diferente de algunos de los cambios que ocurren en las relaciones de género alrededor del mundo. Mientras los roles tradicionales cambian y se cultivan el respeto mutuo y la comprensión, se crea un tipo de matrimonio donde ninguna de 
las partes es necesariamente menor. Esto se debe a que esta relación debe ser una calle de doble sentido y no es constructivo asumir las malas intenciones ni la confrontación absoluta.

Estos diálogos han tenido ya un amplio impacto. Las organizaciones de mujeres, como el Coletivo, han trabajado con más instituciones establecidas, como el Population Council y la Organización Mundial de la Salud, para mejorar el uso de las tecnologías anticonceptivas existentes (como el diafragma) y para desarrollar otras nuevas que puedan ser controladas por las mujeres y ofrezcan protección contra las infecciones. Como resultado de estos diálogos, la investigación biomédica en anticoncepción comienza a ser dirigida no sólo por las oportunidades científicas de investigación, sino también por las necesidades percibidas y expresadas por las usuarias.

Apenas comenzamos a comprender la complejidad y profundidad de los cambios considerados necesarios en el campo de la población y en otros más, y aún buscamos las formas de alcanzarlos. No es una sorpresa que la incitación al cambio encuentre resistencias pues plantea un reto a las estructuras sociales y a los valores religiosos existentes. Esto subraya la importancia de reunirnos para intercambiar ideas y explorar estrategias, para escuchar las voces de la sociedad civil, incluyendo las perspectivas éticas y religiosas. No es suficiente proporcionar buenos servicios a unos cuantos individuos. Debemos también preocuparnos por mejorar la vida de la mayoría de la gente -como el Coletivo ha intentado hacer- a través del diálogo, la defensa, la investigación y la capacitación.

Las integrantes del Colectivo Feminista Sexualidad y Salud son pioneras en las nuevas formas de proveer servicios e involucrar a las mujeres en el cuidado de su propia salud. A través de grupos como éste, el movimiento feminista nos enseña lo que es posible. Debemos estar dispuestos a aceptar el reto. 


\section{Antecedentes}

Este ejemplar de Quality/Calidad/Qualité $(Q / C / Q)$ narra la historia de un grupo de mujeres brasileñas que se formó en 1981. El motivo de su reunión fue su convencimiento -no tan extendido entonces como ahora- de que los enfoques convencionales sobre la salud de la mujer y los servicios de planificación familiar estaban dominados por una perspectiva médica incapaz de dar cuenta de la relación entre sexualidad y anticoncepción, y que además restaba poder a las usuarias.

Este pequeño grupo -cuyas ideas fueron conformadas por sus propias experiencias en las mesas de exploración y en el movimiento prodemocracia- se preguntaba si podría existir una alternativa para las mujeres en Brasil. Ellas empezaron a imaginar qué tipo de servicio auspiciaría una preocupación más amplia por la salud de la mujer, así como por el mejoramiento en su relación con su cuerpo, su sentido de identidad y su dignidad como mujer en la sociedad. ¿Cómo sería un programa así? ¿Qué cuestiones apoyaría? ¿Cómo se organizaría? ¿Cómo hacerlo accesible a mujeres de bajos ingresos? ¿Cómo medir sus logros? ¿Cuánto costaría tratar de realizarlo? A partir de estas preguntas surgió el Colectivo Feminista Sexualidad y Salud (Coletivo Feminista Sexualidade e Saúde) en Sao Paulo, Brasil. Es una historia que invita a quienes estamos preocupados por la salud de las mujeres y su bienestar, a reflexionar, preguntar e imaginar.

\section{Las Primeras Semillas}

El grupo inicial, conformado por cinco mujeres, que se reunió en 1981 partió de la idea de aprender más sobre sus propios cuerpos, compartiendo ese conocimiento y usándolo como base para organizar a otras mujeres en torno a opciones de atención a la salud y anticoncepción, del sexo y la maternidad, de sus derechos. El nombre que escogieron para su grupo refleja los cuatro temas que definen lo que compartían y lo que les importaba: Feminismo, Sexualidad, Salud, Colectividad.

En el transcurso de los siguientes años, mientras el Coletivo estaba trabajando en su proceso educativo, se dieron cuenta de la necesidad de un servicio clínico completo y de gran calidad que respondiera verdaderamente a las necesidades de salud reproductiva de las mujeres. Para 1984 era claro que nadie estaba proporcionando a las mujeres el tipo de servicio que ellas deseaban, entonces las integrantes del Coletivo se fijaron una ambiciosa meta: crear su propia clínica.

La planeación de la clínica tomó dos años. En este tiempo el grupo ya contaba con 11 integrantes, todas de diferente extracción: casi la mitad tenía educación universitaria (incluyendo dos médicas), y la otra mitad era de amas de casa $\mathrm{y}$ activistas comunitarias. Algunas pertenecían a la clase media y otras a las clases pobres. Durante 1984 y 1985, las integrantes del Coletivo se reunieron semanalmente para aclarar sus objetivos, diseñar su programa y capacitándose para iniciar la prestación del servicio.

\section{Fijando Objetivos}

Hablando con muchas mujeres acerca de los servicios de salud, las fundadoras del Coletivo se dieron cuenta de que para la mayoría era degradante hacer una visita al ginecólogo. Los médicos les hablaban, pero no las escuchaban. Para muchas el examen ginecológico era una experiencia violenta, pero, ¿cómo podría el Coletivo convertirla en una experiencia humana y gratificante? Una de las prioridades del grupo era poner remedio al tremendo diferencial de poder entre quienes proveían los servicios de salud reproductiva y sus clientes femeninos.

En Brasil, casi todos los servicios anticonceptivos y ginecológicos son prestados por médicos, la mayoría hombres. Haciendo a un lado las creencias convencionales acerca de qué puede hacerse y qué no, el Coletivo decidió entrenar a mujeres sin estudios superiores para realizar exámenes básicos completos bajo la supervisión de las médicas.

Un segundo paso hacia la humanización de los servicios fue asegurar que la interacción entre el cliente y el prestador de éstos diera como resultado que las mujeres que salían de la clínica tuvieran mayor conocimiento y confianza de sí mismas. Esto significaría hacer un énfasis en la educación que, en su momento, les permitiría hacer más elecciones propias. La información acerca del cuerpo de una y de su sexualidad era entendida como el punto de partida de las mujeres para tomar decisiones efectivas en relación con su sexualidad y salud reproductiva.

Una de las principales preocupaciones entre las integrantes del colectivo fue la fragmentación existente de los cuerpos de las mujeres y sus necesidades de salud en diferentes ramas de servicios. El Coletivo favoreció un servicio integral 


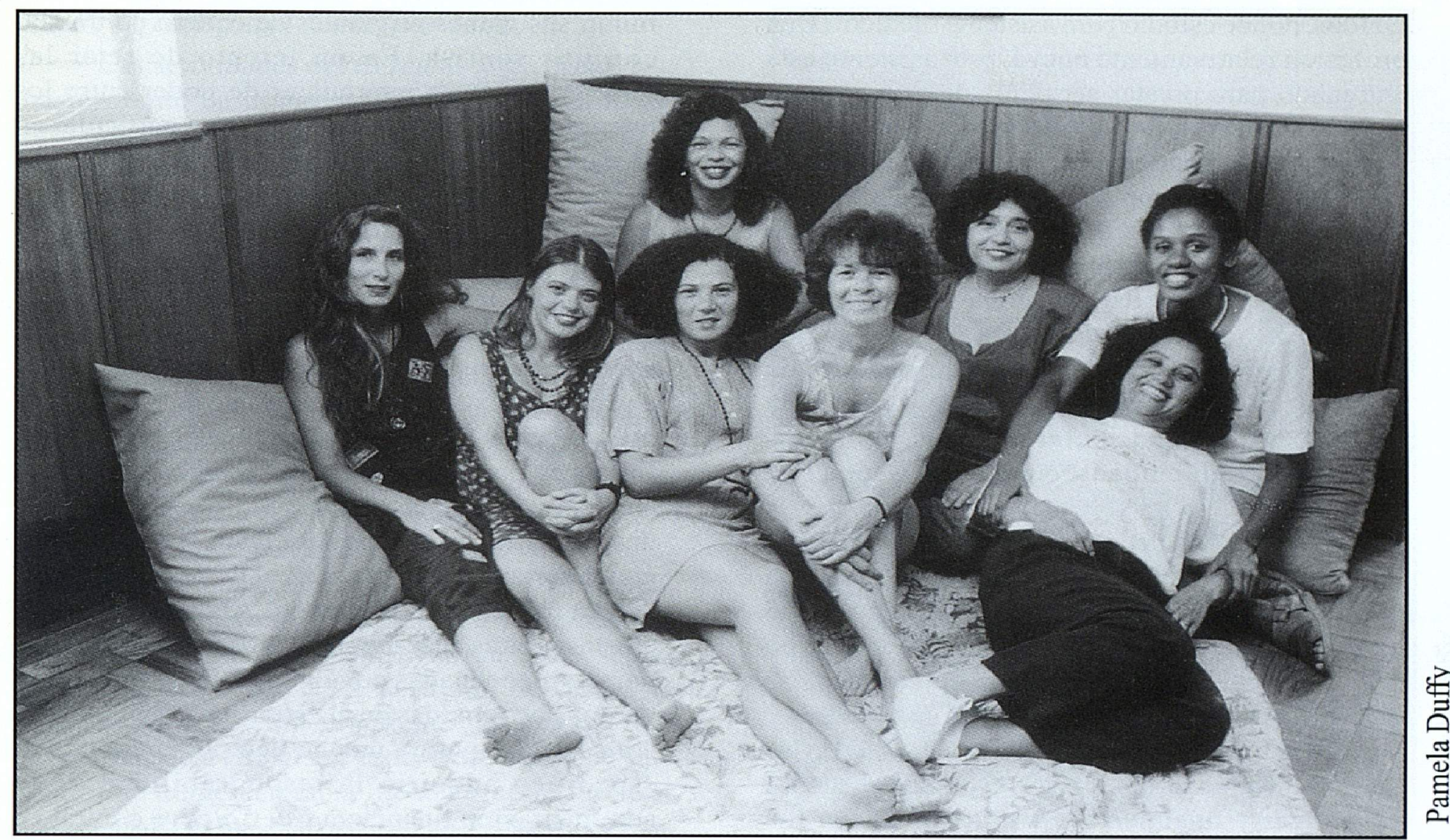

que reconocía que las necesidades médicas de las mujeres están directamente relacionadas con su sexualidad, su papel social, sus actividades económicas y su bienestar emocional. Esto significaría proveer educación nutricional, terapia psicológica y educación sobre derechos reproductivos. Un enfoque integrado también significaba que la misma persona atendería a la cliente en su entrevista inicial y en su examen clínico.

Finalmente, las integrantes del Coletivo sentían que el cuidado de la salud estaba demasiado orientado hacia la medicina curativa, y que la excesiva dependencia de las drogas parecía una competencia técnica. En su lugar, ellas escogieron un enfoque que hacía énfasis en la prevención y el uso de remedios naturales para reducir la dependencia de las medicinas y la tecnología.

Convertir estos objetivos generales en un programa concreto requirió insumos de muchas fuentes. Las integrantes del Colectivo hablaron con todo tipo de mujeres acerca del tipo de servicio de salud que deseaban y consideraron las experiencias del movimiento feminista de la salud en otros lugares. Bajo el patrocinio de ISIS (una organización internacional de mujeres) la integrante médica María José de Araujo completó un entrenamiento de nueve meses en el Dispensaire des Femmes, una clínica de salud feminista de Ginebra. María José explica que esta capacitación fue de importancia fundamental para el Coletivo. "Nosotras nos habíamos imaginado un servicio así, pero nunca lo habíamos visto. Sin embargo, yo vi los mismos principios que discutíamos llevados a la práctica. El Dispensaire había aprendido qué plantas y hierbas podía recomendar confiadamente. Las integrantes del equipo habían creado un nuevo tipo de relación entre paciente y médico. Creían en el poder del conocimiento. Nosotras sabíamos que una clínica en Brasil tenía que ser diferente de una en Suiza, pero esta experiencia fue muy formativa".

A la llegada de María José, convencidas de que su audaz esquema era una posibilidad real, el Coletivo se centró en refinar su programa, desarrollando una base financiera y conduciendo un programa de capacitación.

\section{El Inicio}

Una de las tareas más formidables fue capacitar a las integrantes no médicas para realizar exámenes pélvicos y pruebas básicas de laboratorio. Este proceso fue dirigido por María José y otras dos integrantes, Melodie Venturi y Simone Diniz. Melodie es originaria de los Estados 
Unidos, donde estudió para asistente médico. (Una profesión relativamente nueva, este asistente está entrenado para prestar servicios de primer nivel bajo la supervisión de un médico). Melodie también tenía experiencia previa trabajando en una clínica de salud feminista en su país. Simone es médica. Junto con ellas estaba Rosangela Gramone, una bióloga enviada por el Dispensaire de Ginebra para ayudarlas a iniciar el servicio.

Cada día, durante cinco meses, las integrantes del Coletivo asistieron a sesiones de medio día de duración sobre anatomía y psicología básicas, sexualidad, enfermedades venéreas, anticoncepción, cuidado preventivo y práctica clínica.

Se rentó una pequeña casa en un barrio de la clase obrera de Sao Paulo. Un modesto donativo de Nina Niccim del Dispensaire de Suiza sirvió para comprar las mesas de exploración y el equipo clínico básico. El mobiliario de segunda mano, las lámparas y el refrigerador fueron donaciones.

Las primeras clientes de la clínica fueron las mismas integrantes del Coletivo. Después llegaron sus amigas y finalmente, en 1986, la clínica fue abierta al público.

El día de hoy las integrantes del Coletivo miran sus planes originales de equipo de trabajo con una sonrisa. En un intento de retar las relaciones típicas jerárquicas de poder entre los integrantes del equipo de trabajo -en particular en el ramo de la salud- el grupo decidió que todas aprenderían a hacer todas las tareas de la clínica y que simplemente se rotarían las funciones.

No les tomó mucho tiempo tener que admitir que la gente tiene diferentes habilidades e intereses. Una de las integrantes recuerda: "muchas de nuestras primeras experiencias estaban basadas en fantasías. Nosotras creíamos que todas teníamos más o menos las mismas habilidades e intereses. Entonces pensamos que todas debíamos hacer los análisis y que todas debíamos limpiar. Pero nos dimos cuenta de que algunas de nuestras mujeres nunca serían competentes en el laboratorio, jotras hacían un desastre limpiando! Algunas veces fue chistoso, otras desesperante. Nos pasamos mucho tiempo preocupadas por algo mal hecho antes que darnos por vencidas de nuestras ideas originales". Antes de que pasara mucho tiempo, un individuo específico adquirió la responsabilidad de la administración financiera y el Coletivo contrató a una secretaria que no deseaba realizar exámenes pélvicos.

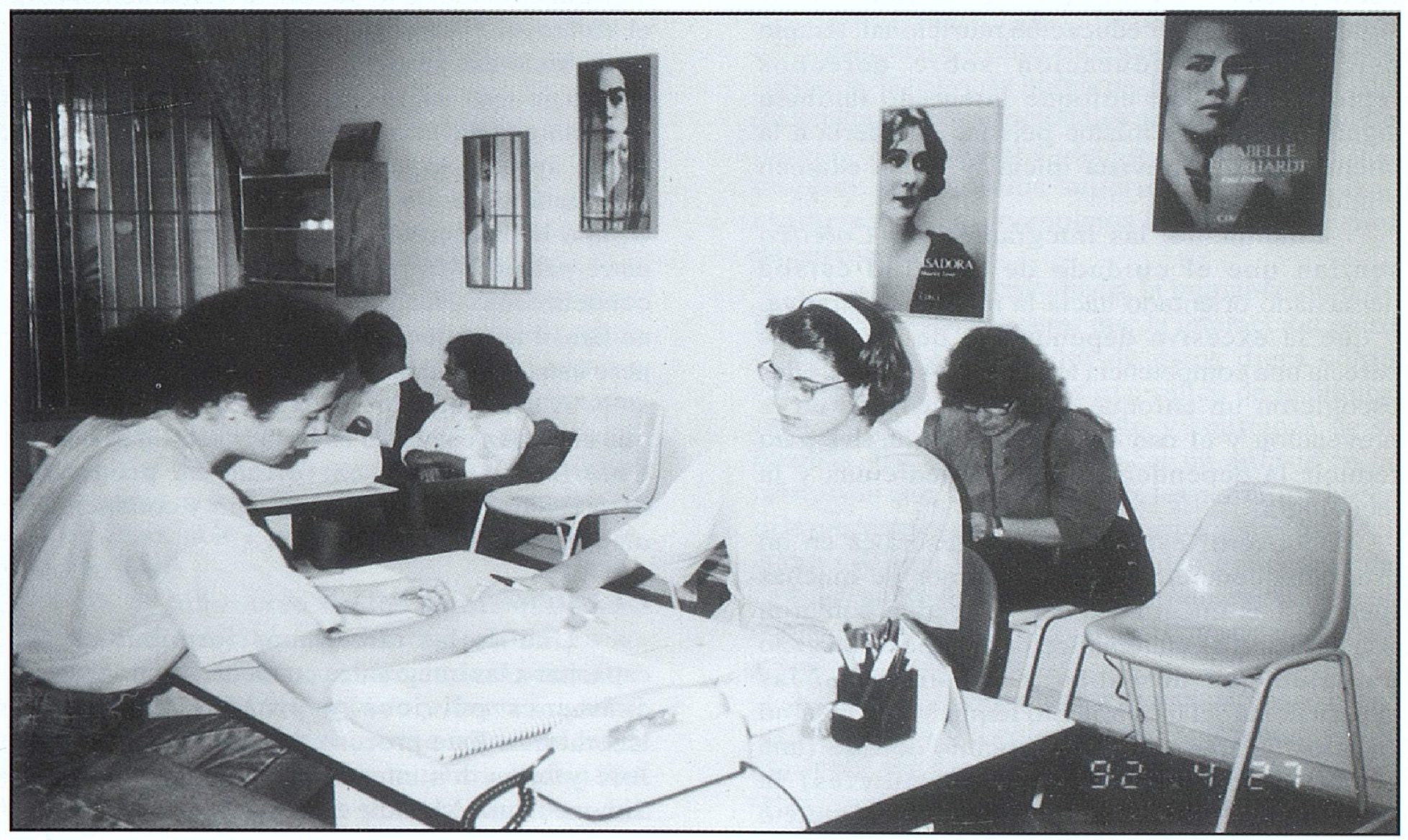




\section{El Programa del Coletivo Hoy}

Las actividades del Coletivo están divididas básicamente én cinco áreas: servicios clínicos, programas educativos, capacitación, defensoría e investigación. Actualmente, el equipo de trabajo está compuesto por 11 integrantes. La mayoría trabaja 20 horas semanales porque el presupuesto no cubre esa cantidad de puestos de tiempo completo. Aunque las tareas administrativas están a cargo de un coordinador designado, las decisiones todavía se toman democráticamente y 1a mayor parte de las integrantes siguen desempeñando más de una tarea. María Otacilia Lima Battistelli, por ejemplo, participa tanto en investigación y capacitación, como conduciendo talleres de conocimiento del cuerpo.

El presupuesto anual del Coletivo es de cerca de $\$ 140,000$ dólares. Anteriormente, las cuotas de las clientes (que están basadas en una escala deslizable) sumaban 28\% del total. Durante los últimos años, el empeoramiento de la situación económica en Brasil ha repercutido en que las cuotas no aumenten en la misma proporción que los costos, y las cuotas de las clientes ahora representan sólo $17 \%$ del ingreso. Ninguno de los programas del Coletivo, incluyendo su programa de capacitación, se sostiene a sí mismo.

Sin embargo, la meta del Coletivo ha sido siempre la de crear un modelo de calidad de servicio más que un modelo autosuficiente; la organización espera seguir dependiendo de donadores externos. El Coletivo se inicio con un pequeño donativo del Dispensaire y actualmente recibe apoyo de fundaciones privadas de Estados Unidos y Europa.

Tampoco los números han sido una prioridad. Sólo cerca de 2,500 mujeres cruzan la puerta del Coletivo cada año (la mayoría únicamente por los servicios clínicos, pero varios cientos por los programas educativos y otros más por ambos) y no existen planes de expansión. El Coletivo mide su éxito como proveedor en su capacidad no sólo de ofrecer una atención respetuosa a las mujeres sino también en la de transformar sus vidas en varios aspectos.

\section{Servicios Clínicos}

Los servicios clínicos inician cuando una mujer llena su propia historia clínica. Junto con la información médica, el formato pregunta si la mujer tiene un compañero constante. Se incluyen otras preguntas sobre si hay dudas acerca de la

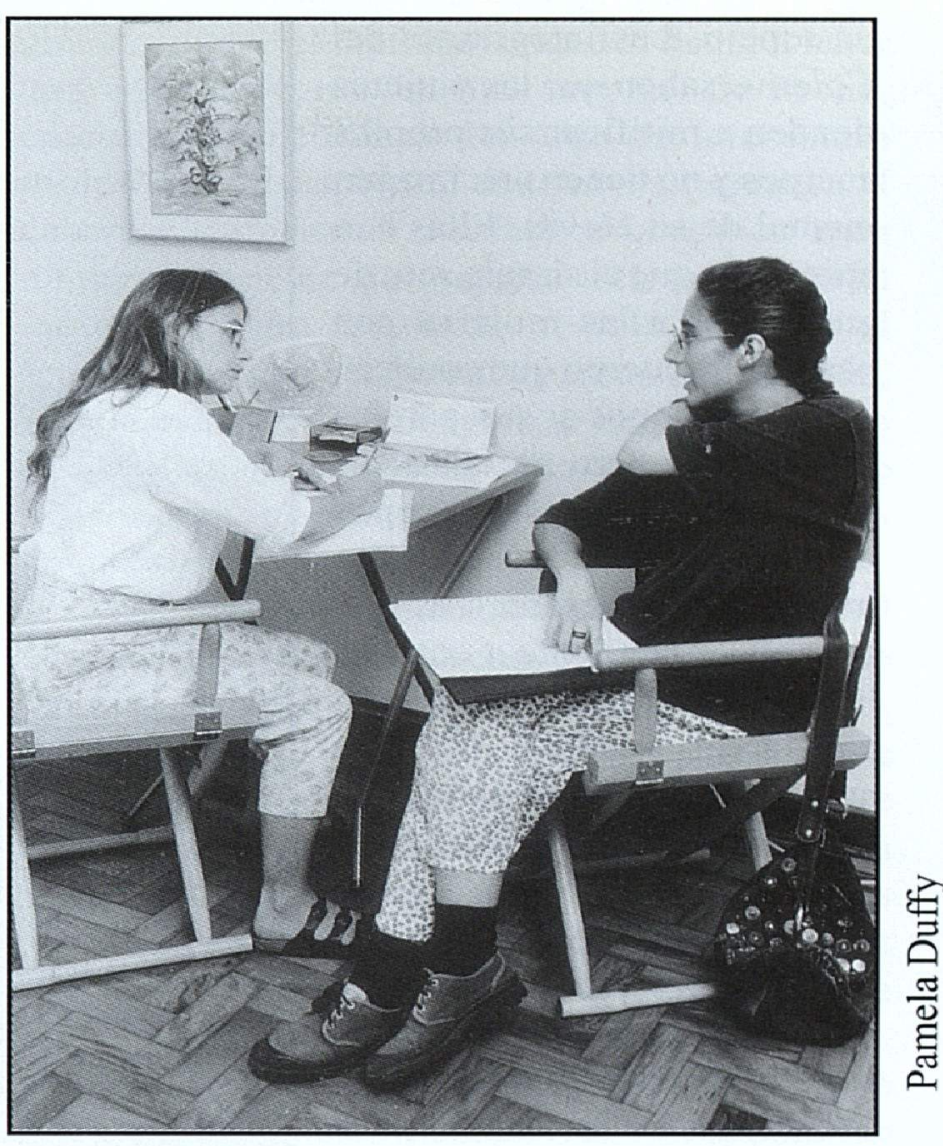

sexualidad y/o si tiene experiencias violentas que le gustaría discutir. Estas preguntas ayudan al equipo de trabajo a enfocar las sesiones de asesoría según la situación personal de cada cliente.

La sesión de asesoría analiza la historia clínica de la mujer y sus preocupaciones. La integrante del equipo de trabajo puede ocupar media hora explicando el diagnóstico temprano, tratamiento y prevención de las infecciones vaginales, permitiendo a la mujer comentar sus experiencias violentas, o discutiendo sobre el estrés relacionado con el trabajo, la fatiga y la nutrición.

Después, con el fin de romper la barrera entre el aspecto social y clínico de la atención y para construir una relación más significativa con la cliente, la misma persona que condujo la entrevista realiza el examen clínico. El examen ginecológico anual incluye una auscultación bimanual y abdominal, un Papanicolaou, palpación de los senos y revisión de la técnica del autoexamen de los mismos. Las médicas están siempre disponibles para consulta en casos difíciles.

Hay algunos aspectos del examen que pueden sorprender a los proveedores tradicionales de planificación familiar. Primero, la mujer se introduce ella misma el espejo. Segundo, se le ofrece la oportunidad de observar su cérvix con 
un espejo. Las integrantes del Coletivo saben que las mujeres tienden a mitificar sus propios cuerpos y no tienen una imagen mental de su cérvix. Ellas han aprendido que el simple acto de enseñarles a las mujeres una parte de su cuerpo que conocen sus ginecólogos y sus parejas masculinas -pero no ellas- las ayuda a reconocer sus cuerpos como propios. Otro aspecto no tradicional del examen es que se invita a la cliente a entrar a la sala de exploración con su pareja; en verdad, un buen número de parejas asiste. El examen incluye también la medición de la presión arterial $y$ el descarte de infecciones del tracto reproductivo y de vías urinarias. Los cultivos vaginales y las pruebas de embarazo se realizan en la clínica, pero las pruebas de Papanicolaou y gonorrea se envían a un laboratorio local. Se dirigen a otros lados para sífilis y pruebas de VIH.

Están disponibles anticoncepción, pruebas de embarazo y cuidado prenatal. Los anticonceptivos que se distribuyen incluyen condones, espermicidas, diafragmas, métodos naturales, pastillas y dispositivos intrauterinos. Esta variedad de anticonceptivos es excepcional para cualquier clínica en Brasil, donde las pastillas y la esterilización agrupan $85 \%$ de todas las usuarias, y los demás métodos prácticamente no se ofrecen. Pocos prestadores de servicios en Brasil saben cómo insertar un DIU, y todavía menos saben cómo medir un diafragma. Las integrantes del equipo de trabajo del Coletivo están totalmente entrenadas en los aspectos clínicos y psicológicos de estos métodos (el DIU es el único método que ofrece exclusivamente el médico) y están comprometidas a permitir que pase el tiempo necesario para asegurarse de que cada cliente sabe utilizar su método de una manera efectiva. Por ejemplo, en la búsqueda de contraindicaciones, las integrantes del Coletivo le preguntan a cada usuaria potencial del DIU, si tiene más de un compañero sexual o si su pareja puede tener a veces otras parejas.

Proveer esta amplia, pero poco usual cantidad de opciones no es fácil desde el punto de 
Brasil y operada por ellas mismas, que es el resultado del crecimiento del movimiento por la salud femenina.

El Coletivo estaba fuertemente motivado a tener disponible el diafragma. En primer lugar, las integrantes estaban preocupadas por la seria carencia de opciones anticonceptivas en Brasil, donde las pastillas permanecen como el único método temporal ampliamente accesible (fuera del aborto ilegal). Ellas albergaban serias dudas acerca del enorme número de mujeres para quienes las pastillas no eran el método apropiado ni por su salud, ni por razones personales. En segundo lugar, por su preocupación por la autonomía de la mujer, estaban interesadas en un método que las mujeres pudieran terminar o empezar (usar o no usar) de manera independiente y que les otorgara alguna protección (al ser usado con espermicidas) contra las infecciones. Finalmente, aunque muchos programas no desean proveer el tipo de educación y consejería requerida para lograr un uso efectivo del diafragma, para la relación cliente-proveedor del Coletivo estas son condiciones sine qua non.

En el Coletivo, la educación sobre el diafragma comienza con una introducción al método. El equipo de trabajo puede enseñarles a las mujeres cómo detectar los periodos fértiles para que no tengan que usarlo todo el mes y sean doblemente precavidas en los días de la ovulación. Dudas sobre cómo afectará el diafragma a las relaciones sexuales se discuten abiertamente y las integrantes del equipo de trabajo a veces sugieren que el compañero masculino sea el que inserte el diafragma como parte del acto sexual.

Durante el examen clínico, a las mujeres que deciden probar el diafragma se les muestra su cérvix con un espejo y se les anima a tocarlo con su propio dedo. María José explica: "uno puede pensar que las mujeres serán demasiado tímidas para tocar su cérvix, pero cuando lo observan en el espejo quedan encantadas. Tienen curiosidad de conocer su propio cuerpo cuando se hace de manera segura para ellas".

La proveedora establece entonces el tamaño adecuado de diafragma para la mujer y se le da la oportunidad de que trate de insertarlo ella misma. Finalmente, se le dan citas para consultas de seguimiento en una semana y en tres meses, sin embargo, se le aconseja que regrese en cualquier momento si tiene algún problema.

Las integrantes del equipo de trabajo del Coletivo sienten que, con la consejería adecuada, métodos como el diafragma pueden llegar a tener una aceptación mucho más amplia. De hecho, cuando otras clínicas del área de Sao Paulo supieron de la disponibilidad del diafragma en el Coletivo, empezaron a referir a la clínica a un número creciente de mujeres interesadas en el método. Como resultado de ello, aunque el programa clínico del Coletivo permanece pequeño, la demanda por el diafragma se ha incrementado constantemente; $40 \%$ de todas las usuarias de anticonceptivos que acuden a la clínica solicitan ahora este método.

El Coletivo también ofrece atención prenatal que incluye no solamente chequeos regulares, sino también asesoría extensiva en nutrición, talleres de parto natural/educación prenatal y grupos de apoyo. Los compañeros masculinos generalmente participan en estos grupos. Ellos aprecian la considerable importancia que se le da a temas como la paternidad y la relación hombre-mujer. Los arreglos para el parto se hacen generalmente con un hospital cercano o una partera.

Además de la asesoría, que es vista como parte de los servicios médicos básicos, el Coletivo proporciona ayuda psicológica más profunda si se necesita. La psicóloga Otacilia Battistelli atiende a algunas clientes hasta durante un año con tarifas basadas en una escala deslizable.

\section{Creando la Relación Cliente-Proveedor}

Como parte del intento por desmedicalizar la atención a la salud, no hay ningún letrero formal en la entrada del edificio del Coletivo. Tampoco encuentran las clientes a nadie ataviado con una bata blanca. Aunque el edificio está limpio, no hay un fuerte olor a desinfectante típico de la mayoría de las clínicas hospitalarias de Brasil. Cuando una cliente entra, es recibida por Ceci, la recepcionista. Si es nueva, se le pide llenar su propia historia clínica. (A aquellas que nó pueden leer o escribir, se les ayuda, por supuesto). Hacer que las clientes llenen su propia historia clínica no es nada más un mecanismo para ganar tiempo. El equipo de trabajo explica que "la participación activa de la mujer en el cuidado de su propia salud empieza en ese momento". La información crítica es también cargada en una base de datos en la computadora.

Un elemento importante de los que hacen único el servicio del Coletivo es el tiempo. Las consultas de primera vez duran alrededor de una hora, y las subsecuentes la mitad. De acuerdo con 


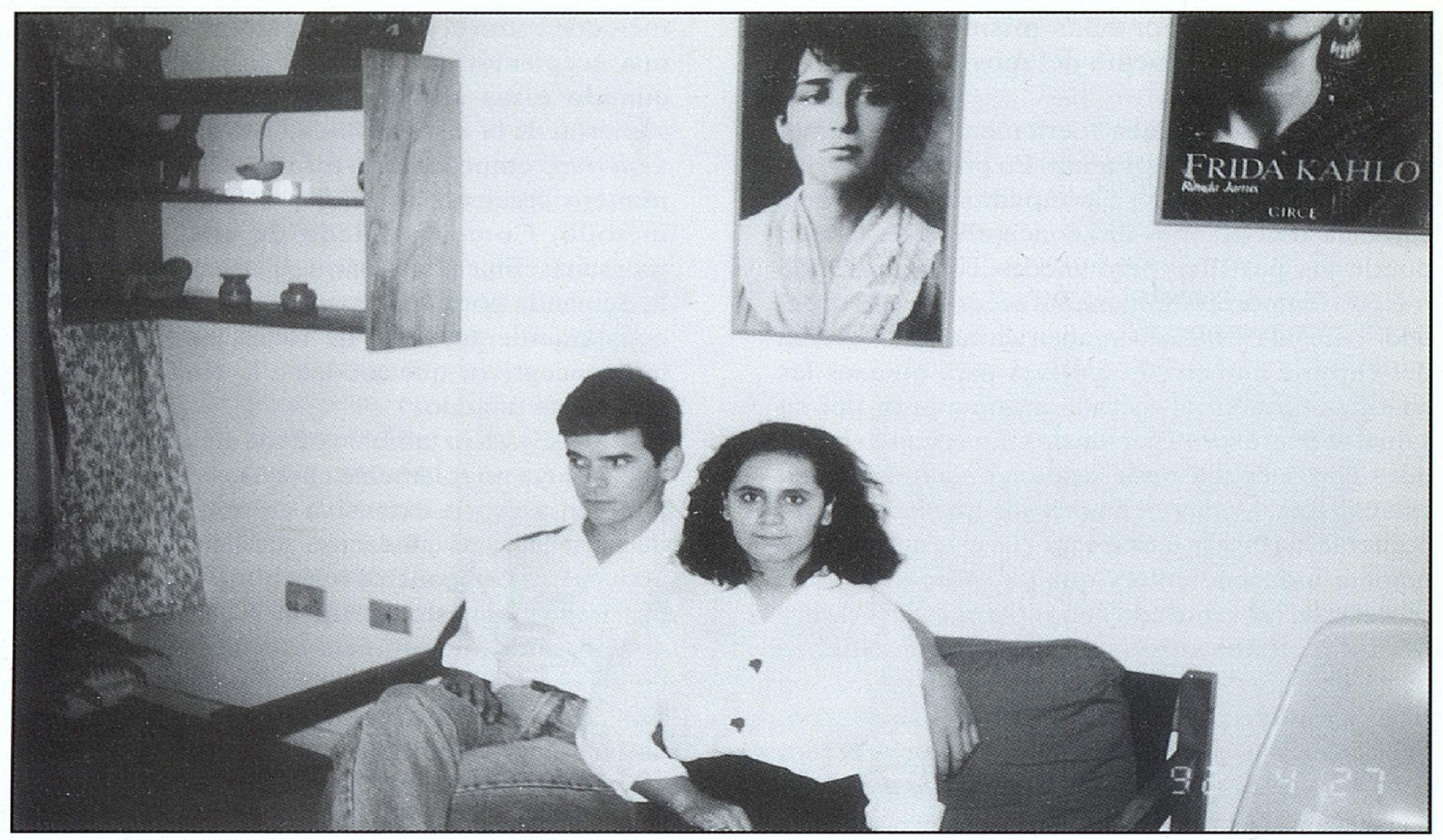

María José: "no hemos tratado de resolver todos los problemas de salud que enfrentan las mujeres, o de atender a toda la población. Estamos tratando de mostrar que un servicio de calidad es posible, pero requiere que dediquemos más tiempo a ellas". Mientras muchas personas en el campo de la planificación familiar lo encuentran poco realista, el equipo de trabajo del Coletivo cree firmemente que sin dedicarles esta cantidad de tiempo, las clientes no serán capaces de aclarar todas sus dudas, aprender acerca de sus cuerpos, de todos los servicios que presta la clínica y de establecer una relación de confianza con su proveedora.

\section{Voces de las Clientes del Coletivo}

Las mujeres que acuden al Coletivo son generalmente de la zona oeste de Sao Paulo, zona que rodea la clínica. La mayoría ( 68 por ciento) de las clientes de la clínica son pobres o de la clase trabajadora. Otro 17.8 por ciento tiene ingresos de clase media ( 5 a 10 veces el salario mínimo), y 14.3 por ciento tiene ingresos de clase media-alta (más de 10 veces el salario mínimo). Considerando que los servicios del sector público en Brasil son gratuitos y que ha estado sufriendo una severa crisis económica, la gran proporción de clientes pobres y de la clase trabajadora que están dispues- tas a pagar aunque sea una pequeña cuota por la atención en el Coletivo es impresionante.

En la actualidad, la mayoría de las clientes del Coletivo conocen la clínica de la misma manera que lo hicieron aquellas de cuando el Coletivo abrió sus puertas: a través de amigas. Creuza y Fernando oyeron del Coletivo por Jorge, un amigo de Fernando. Creuza dice: "Jorge me dijo que este lugar era diferente, que el médico pasaba mucho tiempo contigo, que te prestaban la atención necesaria y que Fernando podía estar conmigo durante la consulta". Mientras espera para que le realicen el examen clínico, Creuza dice que se siente contenta de estar allí porque fue recibida cálidamente y porque le gustó llenar su propia historia clínica. Para ilustrar cuánto vale la calidad en el servicio para la gente, Creuza explica que viajó durante dos horas para llegar al Coletivo porque la buena atención lo vale.

Roberta, de veintiún años es también cliente nueva. Un amigo le dijo que el Coletivo "es un lugar amigable, donde la gente te hace sentir a gusto, y no hay médicos de bata blanca". Roberta ha estado antes en otros servicios, donde el médico la hizo sentirse "como si hubiera sido atacada, humillada". Aquí, en el Coletivo, ella dice que su consulta "fue lo que deseaba. Encontré confort y comprensión". 
Cristina es una soltera de 30 años que ha venido al Coletivo desde que éste abrió. Ella explica: "Cuando yo era una adolescente acudí a un ginecólogo por consejo, porque estaba tomando pastillas anticonceptivas y no me sentía bien. El doctor me dijo que el mejor método anticonceptivo era el matrimonio". Cristina oyó entonces acerca del Coletivo. Ella recuerda su primera visita: "Realmente me conmovió observar mis órganos genitales en el espejo. El autoexamen (cervical) fue lo que más me conmovió". Comentando acerca de qué hace al Coletivo diferente de otros servicios, Cristina comenta: "La consulta es una responsabilidad compartida. La relación médico-paciente es realmente diferente de la de otros lugares". Ella también menciona la disponibilidad de tratamientos alternativos, por ejemplo el uso de yoghurt para ciertas infecciones vaginales, como una ventaja importante.

Crislaine, de sólo 19 años, expresa sentimientos similares. Ella describe el nacimiento de su hijo de 15 meses como un trauma. No le fue permitido estar acompañada de su esposo y, al pedir que alguien le cogiera la mano, el médico le respondió "agarra el barrote de la cama". Después de eso, Crislaine acudió al Coletivo por anticonceptivos. Primero, y más que nada, ella valora el Coletivo por su "respeto a la condición de la mujer".

\section{Programa Educativo}

Como las consultas del Coletivo incluyen significativamente la educación del cliente, el límite entre los servicios clínicos y los componentes educativos es menos obvio que en otras instituciones. Los talleres grupales son la actividad principal del componente educativo. Simone Diniz, Regina Rodríguez, Melodie y María José, todas guían talleres sobre temas como sexualidad, autoestima, adolescencia, síndrome premenstrual, nutrición, anticoncepción, menopausia y embarazo/parto natural. La mayoría de los grupos se reúnen una vez a la semana por ocho semanas, pero el taller prenatal generalmente continúa por cinco o seis meses.

Todos los talleres dependen fuertemente de técnicas interactivas que respetan las experiencias de cada participante, subrayando la creencia del Coletivo en el poder del conocimiento. La transmisión de la información y el intercambio de experiencias sirven como punto de partida para reflexiones más profundas acerca de la identidad de una, como mujer. El comentario de Heliani, de 24 años, al abandonar su primer taller, es típico: "Todo esto me hace pensar acerca de mi cuerpo y mi papel como mujer".
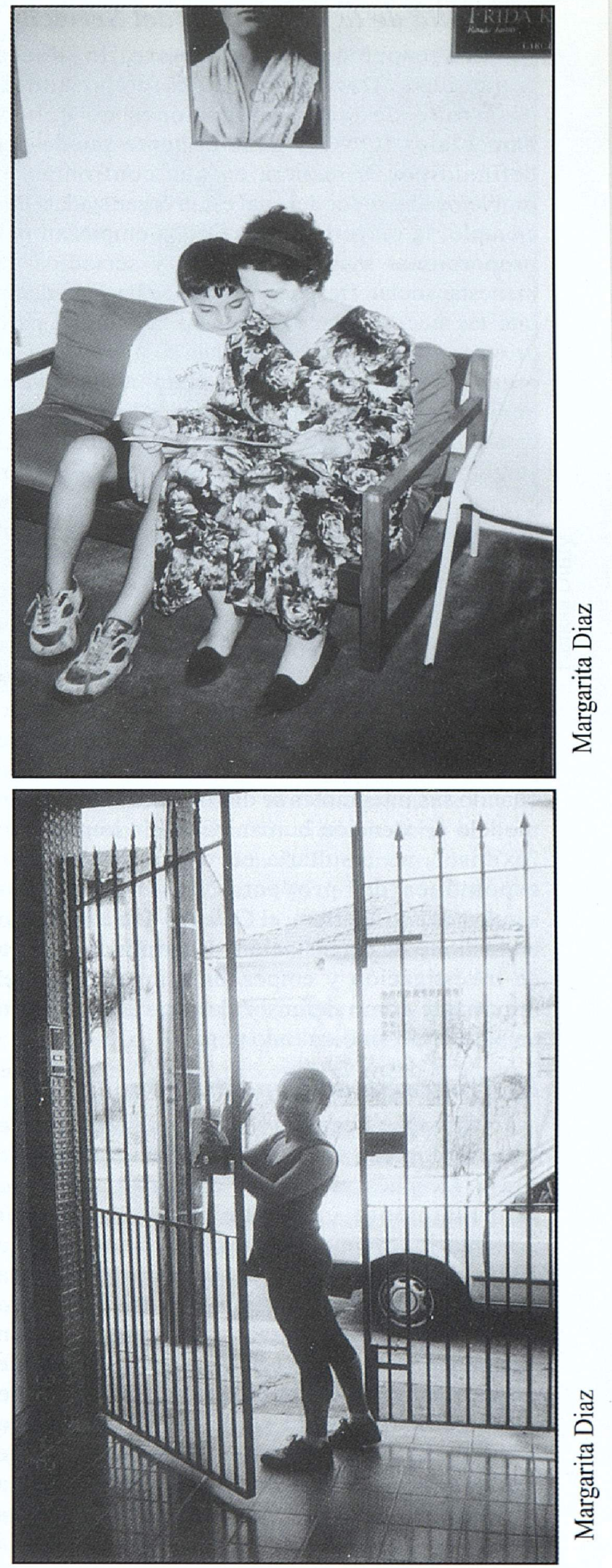


\section{Más Allá de la Prestación del Servicio}

El especialista en desarrollo de la comunidad, David Korten, ha dicho que el desarrollo de las organizaciones no gubernamentales (ONGs) generalmente puede ser definido por la manera en que confrontan el problema alrededor del cual están organizadas. Por ejemplo, la mayoría de las ONGs empiezan por proporcionar ayuda inmediata y servicios de bienestar social. Después, cuando se hace evidente que las necesidades rebasan su capacidad para proveer estos servicios, muchas se involucran en organización y desarrollo comunitarios. Eventualmente, se mueven hacia la resolución de las causas fundamentales del problema a través del cambio de leyes. Las ONGs más avanzadas sirven como actores nacionales y voces pclíticas. De acuerdo con este escenario, el Coletivo inició en una etapa muy sofisticada: no nada más intentaba satisfacer las necesidades individuales a través de la prestación de servicios en pequeña escala, sino que también estaba comprometido a educar a las mujeres sobre lo que está mal en el sistema de salud actual, y a demostrar a los legisladores lo que es posible hacer. Sin embargo, antes de que pasara mucho tiempo se movió a la tercera etapa cuando sus integrantes se dieron cuenta de que un modelo de atención humanizada, sin importar lo "exitoso", no resultaría en una multiplicación espontánea del proyecto. En los tres años siguientes a su apertura, el Coletivo había instalado un instituto de capacitación, desarrollado un área de investigación y empezaba a jugar un papel importante como defensor de una causa no sólo en Sao Paulo sino en todo el país.

\section{El Programa de Capacitación}

Primero, llegaron visitantes interesados de Perú, Colombia, Argentina y otras regiones de Brasil. Después, el Coletivo empezó a patrocinar informalmente entrenamientos y a hacer presentaciones en congresos profesionales. Para 1991, el Coletivo había comenzado un programa formal de capacitación. Actualmente, el Coletivo ofrece tres diferentes cursos para profesionales en el área de la salud. El primero, un seminario de veinte horas sobre salud de la mujer. Abierto tanto a profesionales de la salud como al público interesado, este curso revisa las necesidades de salud reproductiva de la mujer desde la perspectivas técnica y social. Los participantes aprenden acerca de temas como la limitada capacidad de la mujer para protegerse de las enfermedades venéreas, los derechos reproductivos como derechos humanos, los conceptos básicos de sexualidad y educación sexual, y habilidades para guiar un proceso de grupo efectivo. El segundo curso es una versión de mayor profundidad del curso de veinte horas. Aunque el Coletivo distribuye volantes ocasionalmente a profesionales de la salud, recluta a la mayoría de los asistentes por transmisión de información que va de boca en boca. En los últimos años, cerca de 350 participantes, la mayoría mujeres, han asistido a estos cursos. Cada vez más, los participantes vienen de las distintas regiones de Brasil. El equipo de trabajo ha aprendido que los cursos son más útiles a los participantes que tienen reducida o nula exposición a estos temas desde una perspectiva de género; para ellos, el curso los ayuda a modular la manera de percibir a la cliente y los capacita para entender cómo las prioridades de sus clientes pueden ser diferentes de las del sistema de salud.

Tereza es una enfermera que tomó este curso después de haber oído a una compañera de trabajo hablar acerca de él. Ella escribió: "después de una

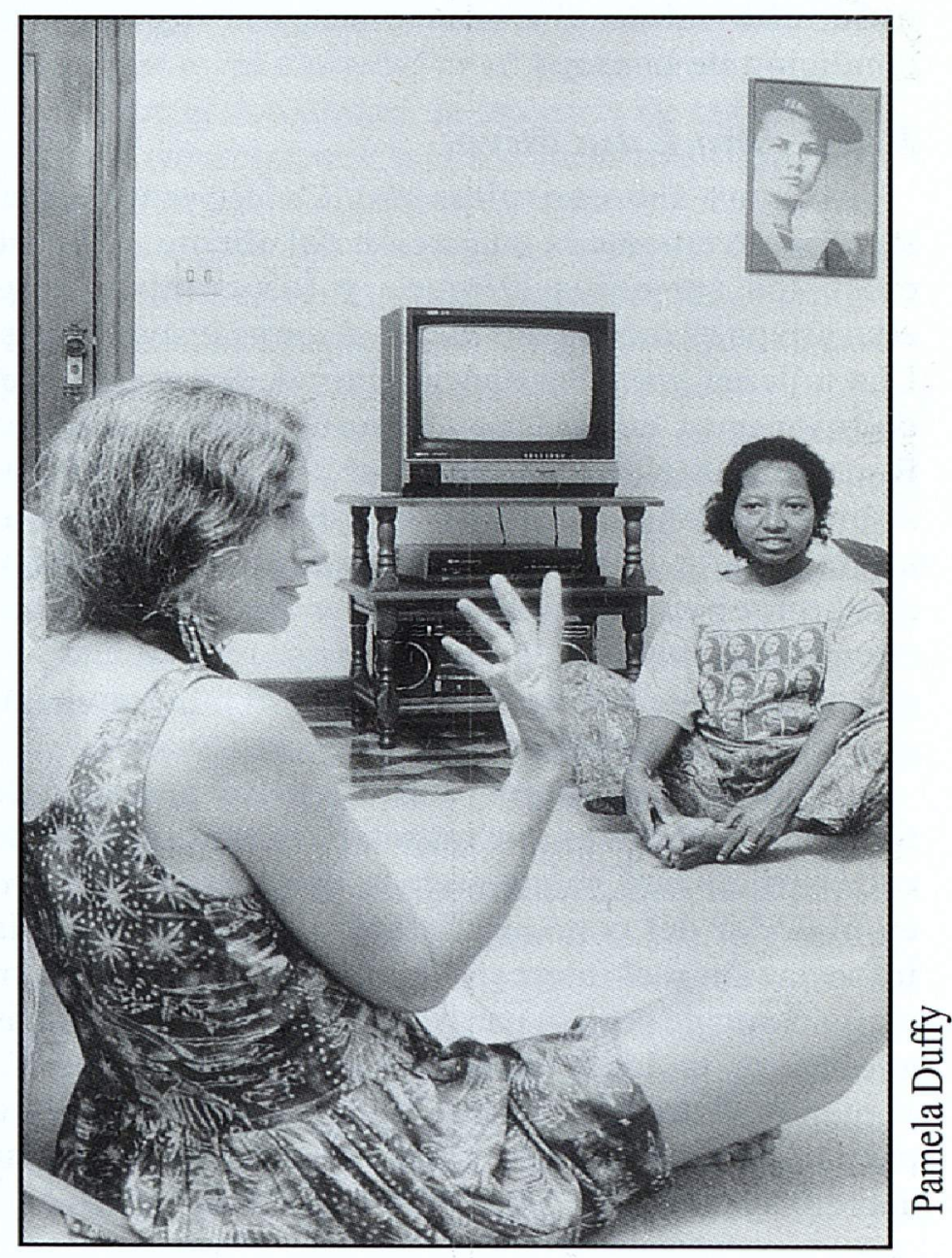




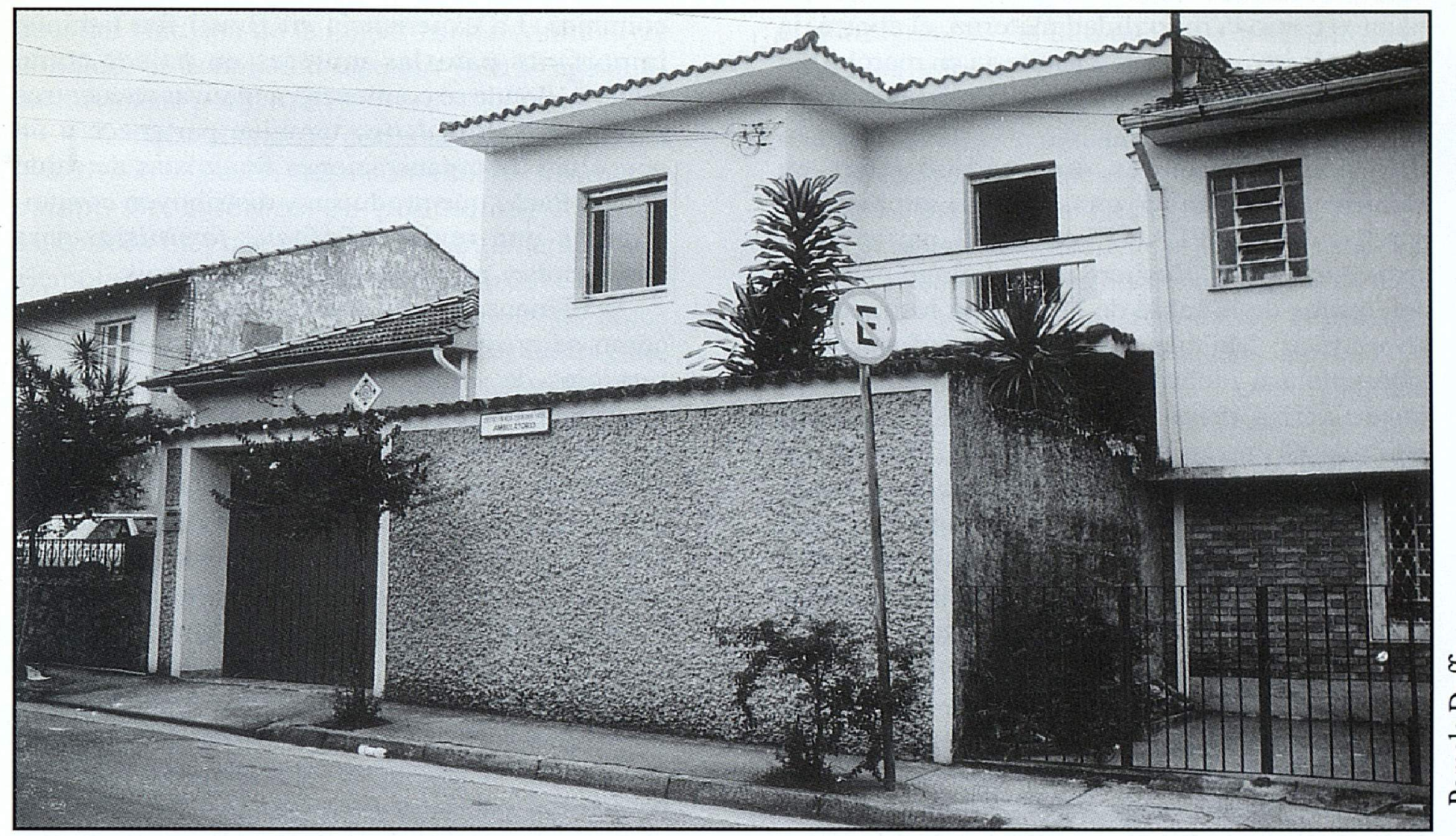

semana de tanta información, yo quería saber mucho más acerca de la salud de las mujeres. Yo no sabía realmente que había tanto que aprender. Esta semana cambió mi vida".

La tercera opción de capacitación es una rotación clínica individualizada en el Coletivo. Está enfocado principalmente a médicos que estén también en el sector educativo o en alguna posición en el sector público donde diseñen políticas. Con una duración de tres meses, este curso muchas veces se enfoca en cómo proveer diafragmas ya que este entrenamiento no está disponible en ningún otro lugar en Brasil. Cerca de cincuenta prestadores de servicio de toda América Latina han asistido al practicum clínico del Coletivo. A pesar de que no ha sido posible evaluar en forma sistemática el impacto de estos programas de capacitación en las vidas profesionales de los participantes, el Coletivo está motivado por el número de "graduados" que convocan a sus colegas y amigos al curso.

\section{Defensoría}

Brasil comenzó su retorno a la democracia a finales de los ochenta, después de décadas de dictadura militar. Muchos de los mismos activistas que en un principio lucharon para restablecer la democracia en Brasil están trabajando hoy en día para hacer esa democracia llena de significado, principalmente a través del trabajo de organizaciones no gubernamentales. El movimiento feminista ha sido esencial en este proceso de construcción de la democracia. Y su compromiso con el desarrollo de una sociedad civil con participación popular y énfasis en los valores y responsabilidad del ciudadano, permanece en el centro de su trabajo.

Verdaderamente, mientras la principal preocupación de las organizaciones de mujeres alrededor del mundo ha sido alcanzar la libertad reproductiva, las feministas brasileñas fueron, probablemente, las primeras en definir los derechos reproductivos explícitamente como un elemento de la ciudadanía. Una de las voces líderes en la promoción de los derechos reproductivos en la agenda del movimiento internacional de las mujeres, ha sido una pequeña y exitosa clínica y programa de capacitación de Sao Paulo: el Coletivo Feminista Sexualidade e Saúde.

Entre los primeros proyectos de defensoría pública, el Coletivo ayudó a impulsar una serie de pláticas (encontros) entre feministas, investigadores biomédicos, representantes de la Iglesia y líderes de la salud pública sobre temas que afectan la salud reproductiva de la mujer en Brasil. Estos encuentros bianuales se han enfocado hacia 
asuntos como la mortalidad materna, el aborto, la ética en la investigación y la puesta en marcha del programa de salud para la mujer, propuesto por el gobierno federal.

Aníbal Faundes, un médico líder en planificación familiar que condujo también las pruebas de NORPLANT ${ }^{\circledR}$ en Brasil, participó en estos encuentros. Recuerda: "el diálogo entre las defensoras de la salud de la mujer y los médicos no es fácil. Muchas veces existe información incompleta e incorrecta en los dos lados, y la pasión verbal dentro de cada grupo no siempre estimula el entendimiento. Cada experiencia de diálogo, sin embargo, es mejor que la anterior, mientras todos escuchamos y aceptamos nuevas ideas, nuevas perspectivas, y entendemos que a pesar de los errores cometidos por ambas partes en el pasado, muchas mujeres y médicos tienen el compromiso común de mejorar la salud y el bienestar de ellas".

Adrienne Germain, vicepresidente de la Coalición Internacional por la Salud de la Mujer (que patrocina los encuentros) explica que "los diálogos dieron a los representantes de diferentes sectores de la sociedad la oportunidad única de conocerse unos a otros y de buscar puntos comunes. La experiencia en Brasil fue también importante para las mujeres en países como Nigeria, donde se comienzan a realizar encuentros similares." El Coletivo también pertenece a un consorcio de organizaciones feministas de salud de Sao Paulo que producen y distribuyen conjuntamente una revista, Enfoque feminista, para defensores y proveedores en todo el país.

El mensaje del Coletivo, acerca de reevaluar cómo se proveen la planificación familiar y los servicios de salud a la mujer, ha sido también escuchado por un gran número de diseñadores de políticas. María José recientemente finalizó cuatro años como directora del Programa de Salud de la Mujer de la Municipalidad de Sao Paulo. Simone Diniz, integrante del Coletivo, fue nombrada también para un puesto gubernamental importante relacionado con los asuntos de la mujer. Una cofundadora del Coletivo, Magaly Marques, fue invitada a trabajar para la International Planned Parenthood Federation/Western Hemisphere Region (IPPF) en Nueva York, en donde coordina proyectos relacionados con la calidad de la atención y el status de la mujer. Otros integrantes del Coletivo han trabajado también como consejeros del Programa Especial de Repro-

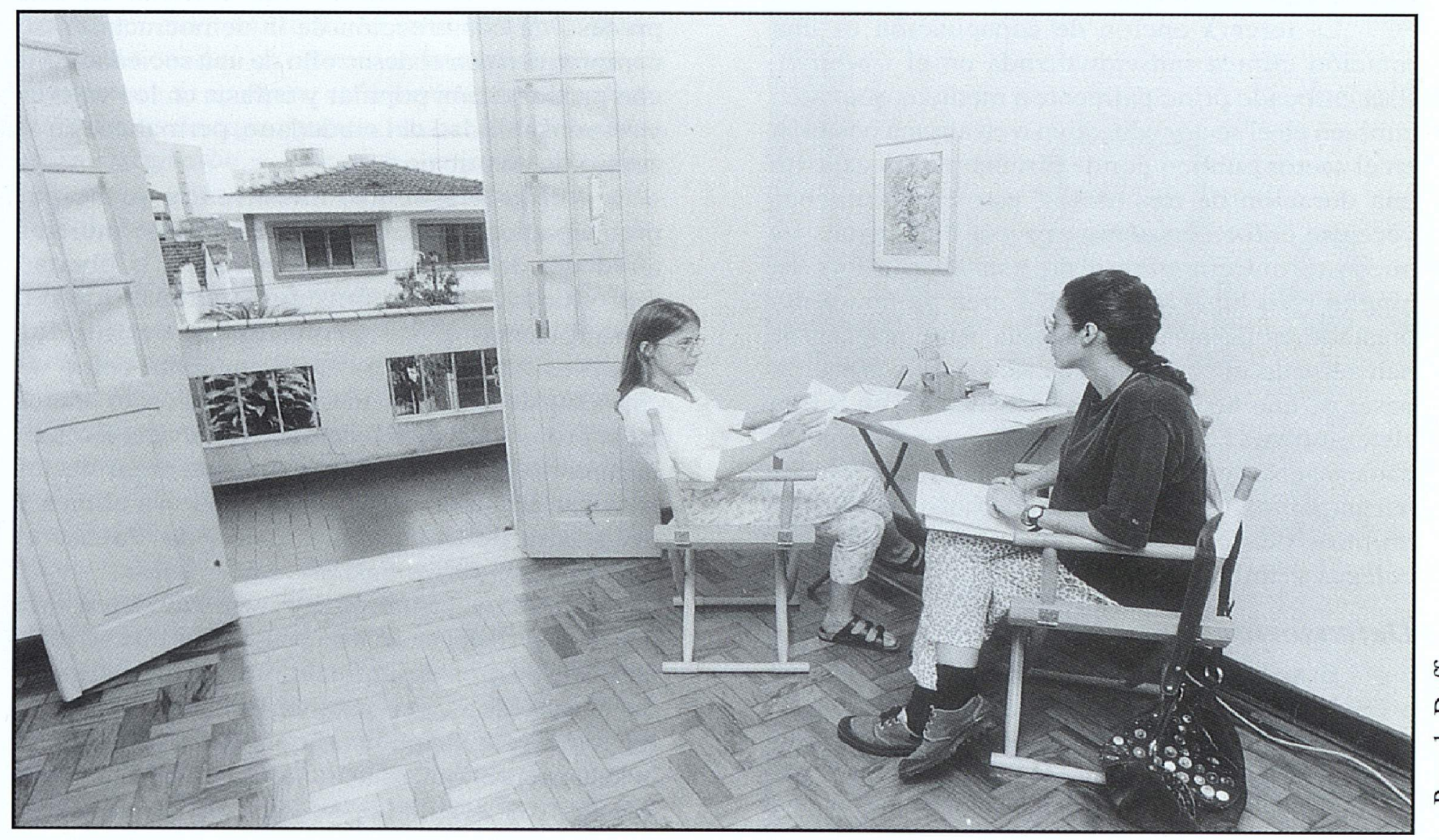


ducción Humana de la Organización Mundial de la Salud, el Population Council y otras agencias patrocinadas por USAID.

Aunque la manera particular de trabajar del Coletivo le ha hecho ganar admiradores dentro del campo de estudios de población, muchos escépticos han cuestionado sus argumentos. Por ejemplo, cuando el equipo de trabajo del Coletivo alegó en conferencias que las mujeres de bajos ingresos podían usar exitosamente el diafragma, muchos profesionales de la planificación familiar y de población querían saber: ¿cuál es la taza de embarazos en estas usuarias? ¿cuáles son sus tasas de continuidad? Como explica María José: "Estas eran preguntas importantes, y nosotras no sabíamos las respuestas. Nos empezamos a dar cuenta de que documentando la experiencia de las usuarias de diafragma no sólo podíamos demostrar la aceptación y la efectividad de éste a los diseñadores de políticas, sino que también podíamos generar información acerca de cómo mejorar nuestros servicios. De esta manera, nuestras preocupaciones por los asuntos políticos y por la calidad de la atención nos guiaron hacia la investigación".

\section{El Programa de Investigación}

A pesar de que el Coletivo ha llevado a cabo una investigación etnográfica informal, documentando la práctica clandestina del aborto, el estudio sobre el diafragma fue su primera investigación formal. En este esfuerzo ellas colaboraron con otros dos proveedores de diafragmas -la clínica de una universidad grande y un médico privado- para analizar los resultados de su uso. El Population Council brindó la asistencia técnica. Los resultados sorprendieron a todos, incluyendo al Coletivo. El primer descubrimiento fue que las tasas de falla del método fueron muy bajas en los tres centros: un impresionante seis por ciento. Las pastillas, el método más popular en Brasil, se piensa que debe tener tasas de falla muy superiores. El segundo hallazgo fue que, después de un año, 72 por ciento de las usuarias nuevas todavía seguían usando el método. Otra lección fue que las mujeres de bajos ingresos son tan capaces de usar este método como cualquier otro grupo. Pero el resultado más sorprendente tuvo que ver con las diferencias entre protocolos y resultados entre los centros. En uno de los centros (no el Coletivo), el proveedor dio a las mujeres instrucciones poco usuales para usar el diafragma: se les dijo que usaran el diafragma sin jalea espermicida, pero que lo tuvieran colocado en la vagina todo el tiempo, retirándolo una vez al día, sólo para lavarlo y reinsertarlo. La efectividad y las tasas de continuidad en este centro fueron las mayores de los tres sitios.

El equipo de trabajo de el Coletivo está evaluando estos resultados a su manera. María José comenta: "vemos estos resultados como una posibilidad, pero estamos intrigadas. Después de discutir los resultados entre nosotras, los compartimos en reuniones especiales con otros proveedores y grupos feministas. Más tarde, organizamos reuniones con nuestras clientes porque creemos que es bueno comunicar los resultados de la investigación con las personas y, además, queremos saber qué es lo que ellas piensan de estos resultados.

"Las mujeres se mostraron muy entusiasmadas con la posibilidad de que pudieran usar el diafragma de forma diferente. Un gran problema con el diafragma es la dificultad de planear las relaciones sexuales con una hora de anticipación o detenerse a la mitad del acto sexual para ponerse el diafragma. El otro problema que enfrentan las mujeres es que la jalea es cara, huele mal y es pegajosa. Si resulta que las mujeres realmente pueden usar el diafragma todo el tiempo y sin usar jalea, este método se convertirá en una opción importante no solamente en Brasil, sino en toda América Latina. ¿Qué significa el hecho de que mientras estamos invirtiendo millones de dólares para desarrollar una vacuna anticonceptiva, todavía no sepamos si el diafragma necesita jalea?"

Otros coinciden en que esta es una pregunta importante. Actualmente, USAID, el Population Council y el Coletivo están involucrados en discusiones relacionadas con un estudio clínico cuidadosamente controlado para examinar el usoefectividad relativo y las tasas de continuidad en el uso del diafragma con y sin jalea. Mientras tanto, los resultados positivos encontrados, aun con la jalea, les ha recordado a las agencias de población que el diafragma es una importante opción que normalmente no está disponible en Brasil ni en otros países. A principios de este año, el Programa Especial de Reproducción Humana de la Organización Mundial de la Salud convocó a un grupo de trabajo interagencias en torno a los métodos anticonceptivos de barrera, involucrando a varias agencias de población internacionales. Este grupo ha hecho de la introducción del diafragma en ciertos países su mayor prioridad. 
La idea para otro proyecto de investigación surgió del proceso de preparación de este artículo. El comité consultivo de $Q / C / Q$ empezó a preguntar si los costos a largo plazo por cliente del Coletivo eran en realidad tan altos como suponíamos. Queríamos saber cuánto se podría invertir en calidad (educación, consejería, oferta de opciones reales) de manera que se pudieran reducir los costos a largo plazo de las consultas subsecuentes, el abandono y el embarazo no deseado entre clientes confusas e insatisfechas. El perfil de bajos ingresos de la mayoría de las clientes del Coletivo hacía esta pregunta aún más relevante. En colaboración con el equipo de trabajo del Coletivo, $Q / C / Q$ patrocinó una investigación para examinar esta pregunta desde varias perspectivas. El estudio tuvo tres componentes y sus resultados son muy interesantes.

\section{Análisis del Costo Por Cliente}

En el Coletivo, el costo promedio anual por cliente, de brindar atención completa a su salud reproductiva, incluyendo anticoncepción, es de alrededor de $\$ 40$ dólares (de $\$ 33.49$ para usuarias de pastillas, hasta $\$ 42.30$ para usuarias de diafragma). Los servicios básicos de planificación familiar y los insumos representan la mitad de este costo. La asesoría (en temas como sexualidad y nutrición), la detección de infecciones del tracto reproductivo, y su tratamiento, equivale a $\$ 10$. Y los últimos $\$ 10$ son el costo del Papanicolaou.

Aunque para la mayoría de los programas en Brasil, diez dólares parece un costo exorbitante para invertir en detección básica, institucionalizar el Papanicolaou universal fue la recomendación prioritaria hecha en el análisis de salud reproductiva de la mujer en Brasil del Banco Mundial. El Banco encontró que la inversión en la reducción del cáncer cérvico-uterino era probablemente la manera más efectiva de salvar vidas y ahorrar dinero al mismo tiempo.

Verdaderamente, el invertir por adelantado sin ofrecer explicaciones es característico del Coletivo. Como la consulta inicial y el examen clínico son tan completos, la mayoría de las clientes nuevas sólo reciben un anticonceptivo en su segunda visita, generalmente una semana después de la primera consulta. El uso del diafragma requiere otra consulta de seguimiento una semana después de medido (aunque no todas las mujeres regresan para esta tercer visita). Así es que $88 \%$ del costo anual total por cliente
(\$37.22 dólares por usuaria de diafragma) se invierte en estas primeras consultas. A pesar de que algunas mujeres regresan para chequeos anticonceptivos, cambios de método o análisis de embarazo, la mayoría de las consultas subsecuentes después de este momento no parecen relacionadas con el uso de anticonceptivos. De los cinco dólares que quedan para gastar en el resto del año, cerca de tres se dirigen al tratamiento de otras dolencias ginecológicas, las más comunes son las infecciones del tracto reproductivo y las enfermedades venéreas. De hecho, el seguimiento anticonceptivo sólo le cuesta al Coletivo cerca de dos dólares por el resto del año. Su enorme inversión en cultivar usuarias de anticonceptivos autónomas y educadas parece resultar en mujeres que regresan al Coletivo con infecciones, bolas en el pecho y otros problemas de salud, pero que generalmente no tienen problemas con su anticonceptivo.

\section{Costo del Uso Efectivo del Diafragma}

Con nuestra segunda serie de preguntas, tratamos de analizar más detalladamente los costos de alcanzar resultados particulares, específicamente de la realización de las intenciones reproductivas de una usuaria de diafragma. ${ }^{1} \mathrm{El} \mathrm{ob-}$ jetivo de una usuaria es evitar el embarazo. Nosotros ajustamos los $\$ 42.30$ dólares del costo anual de atención para que reflejaran la tasa de fallo del diafragma, es decir, para calcular el costo promedio anual de una cliente no embarazada. Esta cifra es $\$ 45.07$ dólares. ${ }^{2}$ Otro de los objetivos de una usuaria de anticonceptivos es encontrar un método que le satisfaga. Cuando nosotros también incluimos en el cálculo la continuidad en el uso del método, los costos anuales de atender a una mujer no embarazada que continúa usando su método después de un año, ascendieron a \$60.99 dólares. ${ }^{3}$ Es importante recordar que estos cálculos suponen también que mejorar su salud reproductiva es parte de las intenciones reproductivas de la cliente.

\footnotetext{
1 Ver Bruce y Jain, Implications of Reproductive Health for Objectives and Efficacy of Family Planning Programs, Nueva York, The Population Council, 1993. Una útil discusión de la intención reproductiva como una valiosa medida del resultado anticonceptivo.

2 Esto se calcula usando el costo total de atender a 100 usuarias por un año, dividido entre el número de esas mujeres que no están embarazadas al final del año.

3 Este es un cálculo similar con el denominador constituido por las mujeres que son al mismo tiempo usuarias continuas y no están embarazadas.
} 


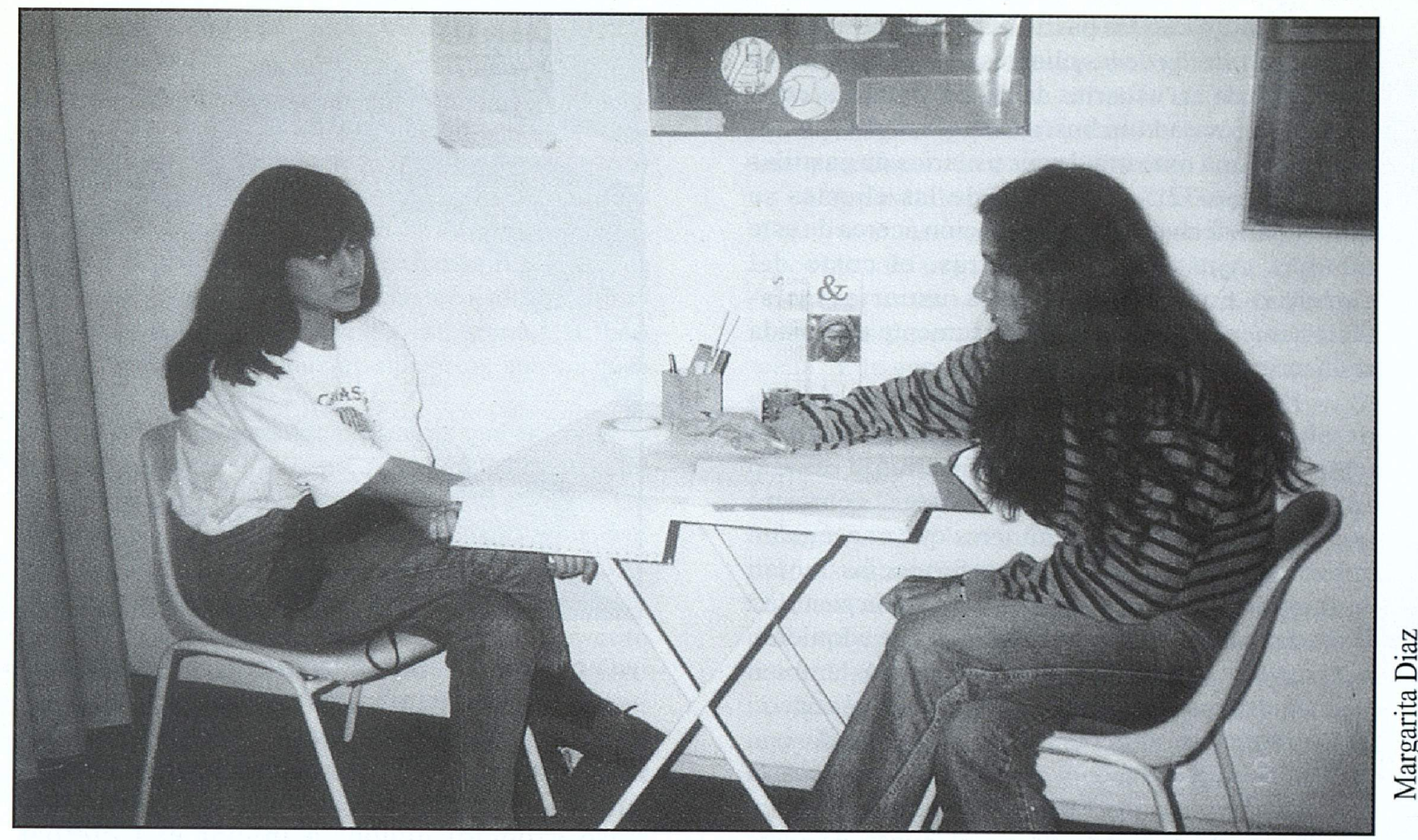

Si nosotros basáramos nuestros cálculos en los $\$ 20$ dólares que cuestan los servicios anticonceptivos solamente (es decir, excluyendo el costo de la atención a la salud reproductiva), el costo por cliente no embarazada sería de sólo \$21.31 dólares y el costo por usuaria continua, no embarazada, sería de $\$ 28.84$ dólares. Ciertamente esta cifra es menor que el costo de proveer NORPLANT $^{\circledR}$, que es de $\$ 23$ dólares solamente por los implantes, más un tiempo considerable de un médico (que se incrementa mucho más cuando se hacen ajustes con las tasas de abandono del método).

Mientras que la última serie de cifras puede aportar mejores comparaciones con los servicios estándar de planificación familiar, también supone que la efectividad del diafragma y sus tasas de continuidad serían las mismas sin el paquete completo de atención a la salud reproductiva del Coletivo. Las integrantes del Coletivo dudan que este fuera el caso, y no tienen interés en averiguarlo; ellas creen que el paquete de salud reproductiva es valioso por sí mismo y no debe verse solamente como un medio de mejorar el uso de anticonceptivos.

En el Coletivo, otro elemento de la "intención reproductiva" de la cliente es el sentirse más conocedora de sus órganos reproductivos y estar más a gusto con ellos. Desafortunadamente, los estudios prospectivos de anticoncepción nunca han incluido el autoconocimiento y los niveles de confort como una variable en los resultados. Aunque existen datos anecdóticos importantes que indican la relevancia de ese conocimiento y confort para las clientes, no tenemos datos cuantitativos que nos permitan medir la tasa con que este resultado se alcanza.

\section{El Costo de Alcanzar un Resultado Deseado: El Uso de Anticonceptivos Orales}

En Brasil, las pastillas anticonceptivas están disponibles en el mostrador. El precio de venta de 12 cajas de pastillas de la marca proporcionada por el Coletivo es de aproximadamente $\$ 24$ dólares. Obviamente, este costo es considerablemente menor que los $\$ 33.49$ dólares que cuesta al año el paquete completo de salud reproductiva más las pastillas en el Coletivo. Pero, ¿qué clase de resultados se alcanzan a través de la venta de mostrador de la pastilla?

Queríamos saber cuánto le costaba al Coletivo cada usuaria, a la vez clínicamente indicada y satisfecha con la información que había 
recibido junto con las pastillas. ${ }^{4}$ Una auditoría de la historia clínica de las clientes mostró que el 100 por ciento de las usuarias de pastillas del Coletivo había sido revisada en busca de contraindicaciones básicas, y una muestra de sus usuarias de pastillas informó que 72.5 por ciento de las clientes se sentían satisfechas de la información acerca de este método. Ajustando estas cifras, el costo del Coletivo por atender a una usuaria satisfactoriamente informada y clínicamente apropiada se incrementa a $\$ 46.19$ dólares. $^{5}$

En ese momento, se llevó a cabo un estudio paralelo con las mujeres que siempre habían obtenido las pastillas en una farmacia. Un estudio anterior hecho por Hardy y sus colegas demostró que la cuarta parte de las mujeres que conseguían anticonceptivos orales en las farmacias tenían contraindicaciones absolutas para usar la pastilla. ${ }^{6}$ En nuestra muestra, de 141 mujeres que adquieren sus pastillas regularmente en la farmacia, también se encontró que sólo 16 por ciento se satisface con la información sobre el método. Ajustando con estos resultados, el costo de alcanzar una usuaria de pastillas satisfecha con la información y mínimamente indicada desde el punto de vista clínico, a través del mostrador, se eleva astronómicamente de \$24 a \$200 dólares. ${ }^{7}$ Desde cualquier perspectiva de política que respete el filtro clínico y el consentimiento informado, el enfoque a fondo del Coletivo ahora se ve apropiado.

El Coletivo desarrolló su programa basándose en la creencia de que existen recompensas sociales para una sociedad que ayuda a las mujeres a volverse más autónomas en sus vidas sexuales. Este extenso análisis de los costos, en combinación con el estudio del Banco Mundial, sugiere que también existen recompensas financieras. ${ }^{8}$ Muchos donantes están ahora reconsiderando los limitados indicadores usados en el pasado (como el año protección pareja APP, y el número de nuevas aceptantes) a favor de indicadores más significativos de la salud reproductiva y de la regulación satisfactoria de la fecundidad.

\section{Las Integrantes del Coletivo Hablan Acerca de los Altibajos.}

$¿$ Ha habido dificultades y dudas en el camino? Por supuesto.

Hace diez años Rosa Dalva Faustinone Bonciani estaba entre las fundadoras del Coletivo. Ahora, a sus 42, reflexiona sobre sus preocupaciones personales y las del grupo: "En ese tiempo

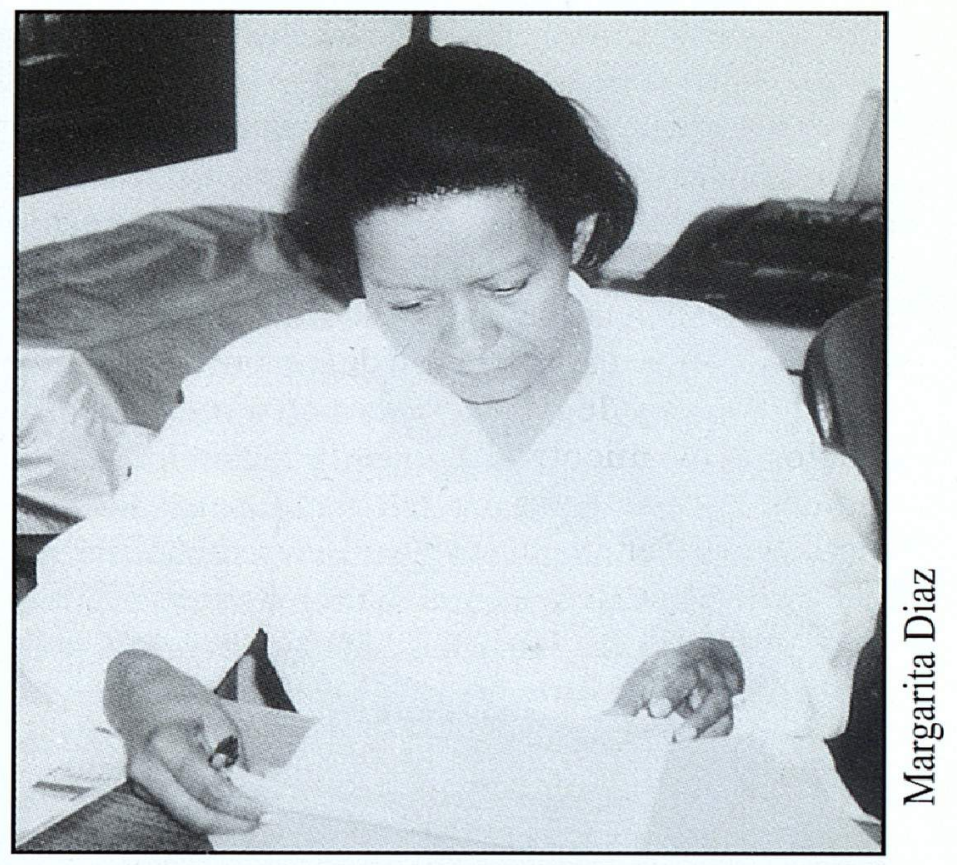

yo no sabía que este sería un proyecto de vida. Yo vengo de una familia muy pobre, del campo, y estaba estudiando para convertirme en farmacéutica. Había abandonado mis estudios para atender a mis dos hijos. Entonces conocí a María José y decidí ayudar a iniciar el Coletivo. Finalmente acabé mis estudios, pero nunca trabajé realmente en esa área. Así es que no tengo una profesión, en el sentido formal, que me respalde. El trabajo tiene sus dificultades. Este es un laboratorio. Nosotras aprendemos, inventamos una nueva manera de trabajar. No es fácil tratar de vencer viejas y cristalizadas maneras de ser personal y profesionalmente".

A pesar del énfasis en la igualdad, el "status" todavía juega un papel. Muchas veces son las médicas, María José y Simone, quienes son invitadas a participar en encuentros internacionales. Esto provoca tensiones especiales en

${ }^{4}$ El uso bien informado es parte del consentimiento informado básico; la satisfacción de la cliente junto con el proceso de información fue seleccionado como el más práctico indicador para este estudio. Otros indicadores de uso bien informado también aparecen en los estudios hechos.

5 Nuevamente se llega a la cifra ajustada calculando el total del costo de proveer a 100 usuarias de pastillas con atención completa a su salud reproductiva mas anticoncepción por un año, dividido entre el número de esas mujeres que están satisfactoriamente informadas y son apropiadas clínicamente hablando, es decir, $\$ 33.49 \times 100 / 72.5$.

${ }^{6}$ Hardy E.E., et al., "Contraceptive pill: adequacy of use among women in unions. [Adequacao do uso de pilula anticoncepcional entre mulheres unidas]", en Revista de Saude Publica, vol. 25, núm. 2, pp. 96-102, 1991.

${ }^{7}$ En este caso, el cálculo es $\$ 24 \times 100 / 16 \mathrm{x} .75$.

${ }^{8}$ Los investigadores están preparando en este momento una discusión más detallada del estudio de costo-efectividad para publicarlas por separado. 
el Coletivo, porque es difícil contratar a otras médicas que acepten unirse a una organización no jerarquizada que paga sueldos bajos.

A través de los años, varias integrantes han pedido licencias para seguir otros intereses y luego regresar. Varias han restaurado su entusiasmo original y su compromiso mediante oportunidades para viajar y encontrarse con defensoras feministas de la salud y legisladores en el ámbito internacional. $\mathrm{Y}$ mientras nuevas integrantes se han unido, algunas antiguas compañeras han partido para no volver.

Pero el más grande problema que el Coletivo ha enfrentado es el mismo que el de la mayoría de los programas: financiamiento. Rosa explica: "la parte más dura ha sido la falta de seguridad profesional en el empleo. Dependemos constantemente de recursos externos. Como resultado de lo limitado de nuestros recursos solamente alcanza para que yo trabaje medio tiempo y tengo que trabajar en otro lado para sostener a mi familia". Dado que se encuentra fuera del círculo de programas patrocinados por los principales donantes en población como USAID, el Fondo de Población de Naciones Unidas o la IPPF, el Coletivo ha confiado en el apoyo de la International Women's Health Coalition, la MacArthur Foundation, fundaciones europeas y otros donadores privados. Las cuotas de las clientes continúan cubriendo una parte significativa de los costos, pero completar el resto de los gastos ha sido siempre -y probablemente siempre lo seráuna preocupación para el Coletivo.

A pesar de los problemas, las integrantes del Coletivo insisten en que su trabajo es una fuente enorme de orgullo personal. Rosa explica: "Seguro, es un reto constante. Pero cada vez que damos un paso adelante sentimos que esto vale la pena. Y la gente me admira por trabajar aquí, aún cuando no entienden bien que es el Coletivo. Se sienten conmovidos. A mi hermano mayor le parece muy interesante que llegué de una aldea rural, tuve seis hermanas y terminé aquí! ¿La respuesta? No lo sé. Algo que encontré en mí me impulsó a rebelarme en contra de la sumisión y la dominación -incluyendo la dominación económica- que es el machismo, tan fuerte en el campo".

Celia Cipriano, de 31 años, se unió al Coletivo hace seis años al contestar un anuncio clasificado que solicitaba una contadora. Ella sonríe y recuerda: "Yo no había oído nunca de colectivos feministas. Me daba miedo. Estuve un poco perdida los primeros seis meses, mientras aprendí sobre la salud y otros temas de mujeres. Pero creo que hago una contribución importante aquí. Y he crecido mucho personalmente. Voy a

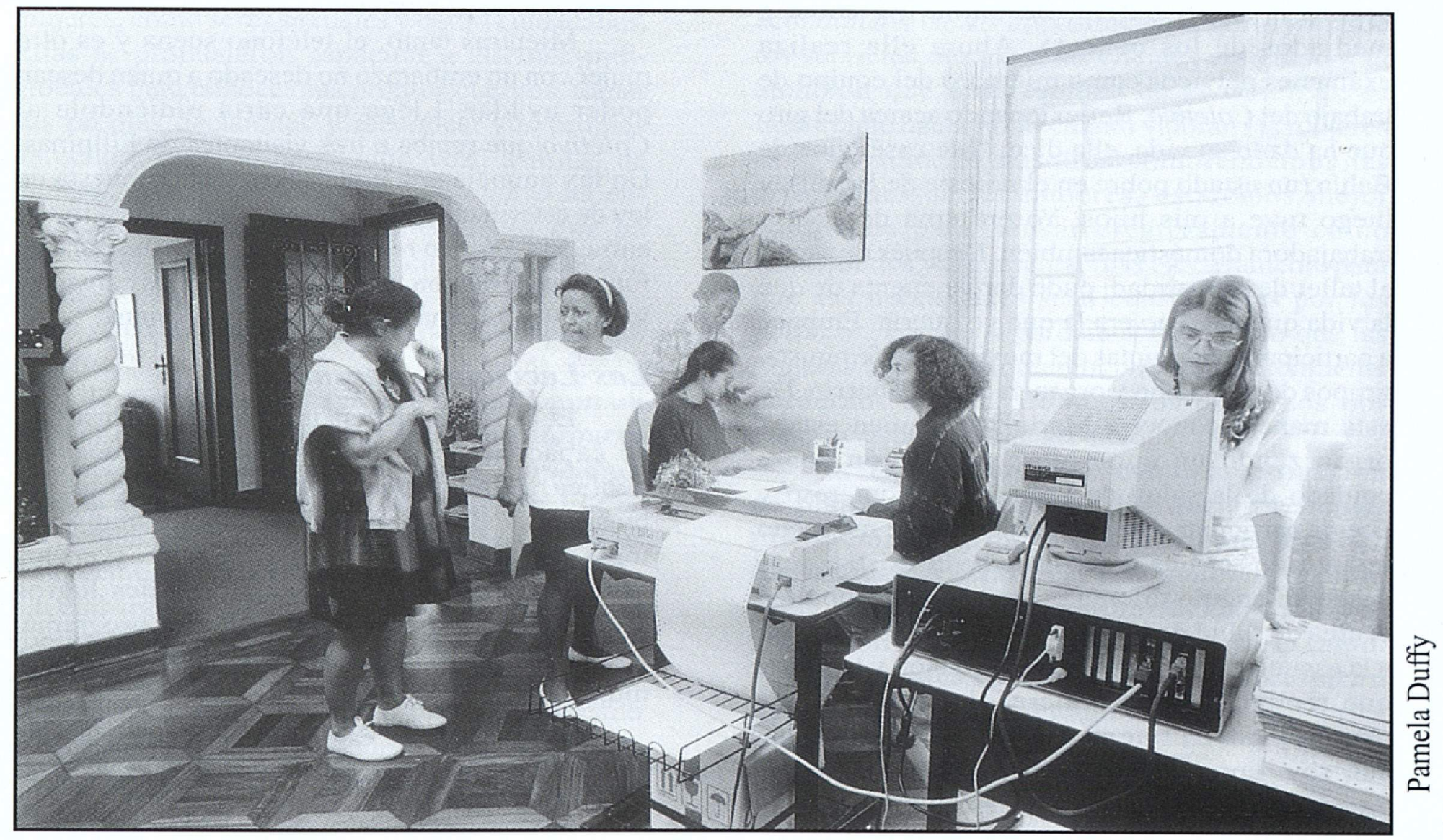


conferencias. Trato particularmente de ir a conferencias sobre el aborto y sobre cómo usar el humor en el trabajo. E invito a mis amigas aquí. A la gente le encantan los talleres, como el que se llama 'Nuestros sueños'. Mi madre, Sofía Elías Cipriano, trabajó también aquí por un tiempo. Todavía lo hace a veces, cocinando y limpiando el local. Mi madre tiene educación primaria. Aquí se enteró de otra forma de vida para ella, entre gente que es muy abierta y amigable." Le preguntamos a Celia acerca de las desventajas de trabajar en el Coletivo. Ella nos dijo que "todavía no las encuentra".

Simone Grilo Diniz es una médica y feminista de mucho tiempo. Además de proveer asesoría clínica en el Coletivo, Simone está involucrada en investigación y capacitación. Ella explica: "Antes del Coletivo, yo tenía mi trabajo como activista feminista, por un lado, y mi trabajo como médica, por el otro. El Coletivo me permitió unir estas partes de mí misma y me ha permitido ver que los problemas que experimentamos como mujeres no son solamente nuestros, personales y aislados. Esto ha tenido un buen impacto en $\mathrm{mi}$ autoestima. En este sentido, tener un compromiso político activo se vuelve muy tranquilizante".

María Jucinete De Souza se inscribió en un grupo de salud y sexualidad que el Coletivo organizó en su barrio, de bajos ingresos, a mediados de los ochenta. Ahora ella realiza exámenes pélvicos como miembro del equipo de trabajo del Coletivo. Reflexionando acerca del giro que ha dado su vida, ella dice: "Me casé, vine de Bahía (un estado pobre en el noreste de Brasil), y luego tuve a mis hijos. Yo era ama de casa y trabajadora doméstica también. Después de asistir al taller de sexualidad, pude darme cuenta de que la vida que tenía no era la que yo quería. Empecé a participar en las juntas del movimiento feminista, grupos de relajación y organización del barrio. De esta manera conocí a María José, quien estaba organizando un curso de capacitación sobre cuidado de la salud de la mujer. Me interesó y decidí participar. Me di cuenta de que mi sueño infantil de ser una maestra todavía existía, pero desde un ángulo diferente: ser una educadora en el área de salud de la mujer. Aún cuando yo no fui a la escuela secundaria, la capacitación y la ayuda que recibí de otras mujeres del Coletivo me permitió convertirme en una auxiliar de salud, que aún soy. Los cambios personales han sido tan grandes, comparados con las tareas que yo hacía como ama de casa. Ahora tengo la oportunidad de mejorar económicamente y también de crecer como individuo capaz de tener logros. Cada día que las clientes regresan a la clínica o les cuentan a sus amigas acerca de nosotros, yo siento que estos logros son reconocidos".

\section{Los Siguientes Pasos}

A principios de los años noventa, la renta de la clínica del Coletivo había aumentado hasta constituir 20 por ciento de su presupuesto total. Así que en 1993, con fondos reunidos tanto en Brasil como en los Estados Unidos, las integrantes del Coletivo realizaron uno de sus más grandes sueños: compraron su propio local. Ubicado enfrente de su dirección original, el nuevo Coletivo se encuentra en una residencia antigua, grande, bonita y espaciosa. Desde que se mudaron, los costos de operación han disminuido significativamente, ofreciendo al grupo una seguridad marginal. Pero más allá de esto, las integrantes del equipo de trabajo sienten un nuevo orgullo y confianza en la estabilidad de la organización. El equipo de trabajo del Coletivo desea actualmente elaborar la siguiente fase en la investigación sobre el diafragma, colaborando con el análisis del costobeneficio, añadiendo algunas nuevas integrantes (especialmente otra médica) y explorando el tema de involucrar al hombre.

Mientras tanto, el teléfono suena y es otra mujer con un embarazo no deseado a quien desean poder ayudar. Llega una carta pidiéndole al Coletivo que reciba a tres visitantes de Filipinas. Un fax anuncia una junta sobre una propuesta de ley de esterilización. La puerta se abre y una mujer entra. El Coletivo recuerda, una vez más, por qué funciona. Esas son las bendiciones y las cargas de lo que Rosa llama " un trabajo apasionante".

\section{Las Lecciones Aprendidas}

El Coletivo maneja una clínica, un instituto de capacitación y un programa de educación pública. Proporciona un liderazgo al gobierno brasileño y al movimiento de salud feminista, y toma parte activa en la investigación y en los asuntos políticos internacionales. Tales logros serían impresionantes para cualquier programa. Recuerde, lector, que este es un grupo de sólo 11 mujeres.

Basadas en sus experiencias personales, las integrantes del Coletivo nunca perdieron la fe de que, conociendo sus cuerpos y participando 


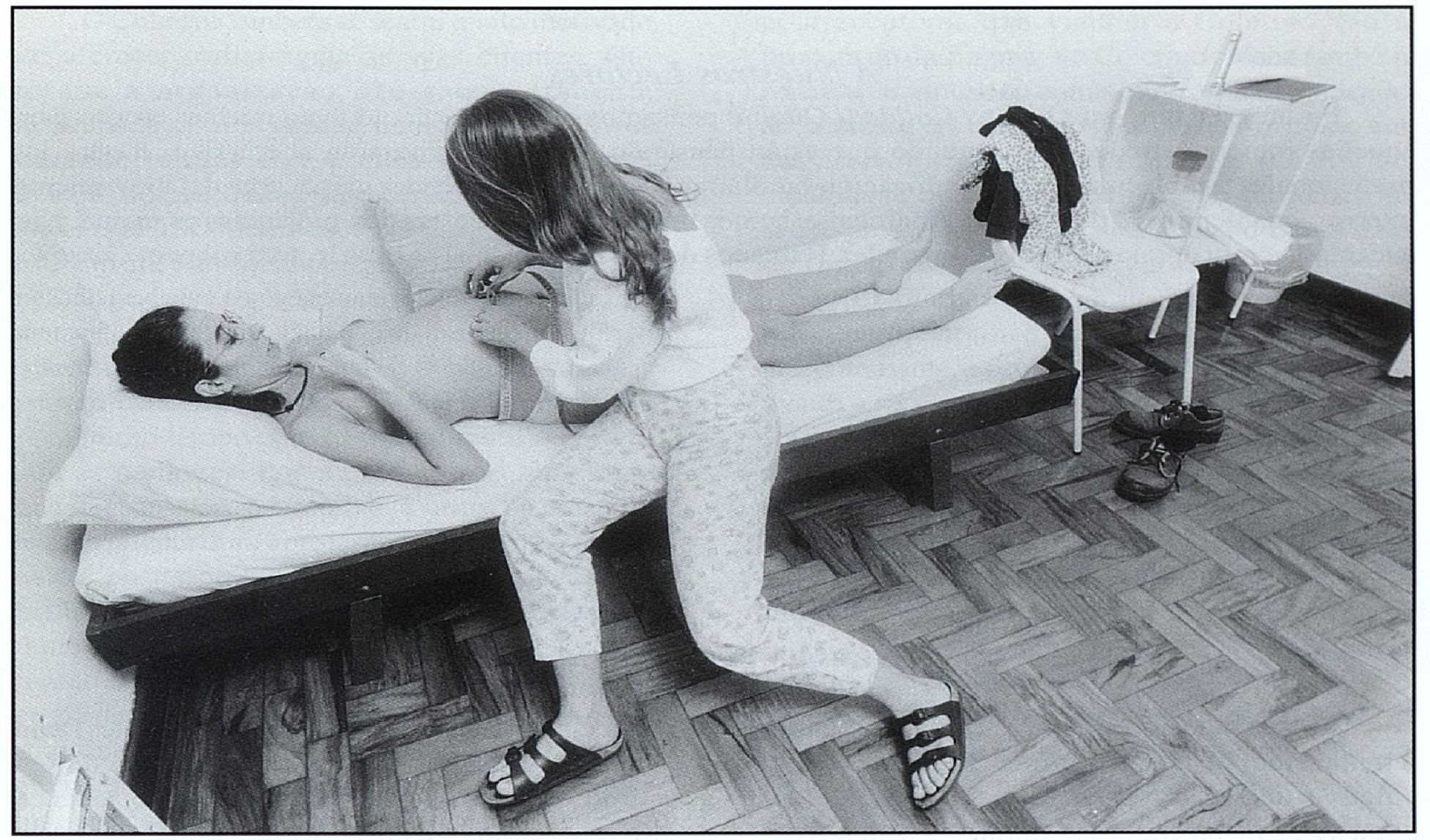

activamente en el diseño de su propio servicio de salud, podían mejorar no solamente su estado físico sino también fortalecer su identidad como mujeres, como seres sexuales y como ciudadanas. Ellas se propusieron capacitar a clientes individuales para conocer sus propios cuerpos, tomar sus propias decisiones y reconocer sus propios derechos. Ellas le han "dado voz" a miles de mujeres. Doce años después, el Coletivo ha encontrado su propia voz, tomando lo que ha aprendido al proveer los servicios y hablando al mundo.

\section{Coletivo?}

¿Qué podemos aprender de la historia del

1. Conociendo para qué trabaja, aun un pequeño programa puede tener un impacto enorme en la formación de ideas y opciones para la atención de la salud de la mujer. El $\mathrm{Co}$ letivo nunca se desvió de sus objetivos originales y su membresía ha permanecido bastante estable. Sin embargo, se las ha arreglado para evolucionar continuamente, permaneciendo abierto y flexible a nuevas ideas y diferentes perspectivas. Más que descansar en sus laureles, el Coletivo ha buscado constantemente nuevos aliados y nuevos caminos en un esfuerzo para llegar lo más cerca a sus ambiciosas metas.
2. Las mujeres valoran mucho los servicios que satisfacen lo que ellas consideran sus necesidades de salud. Aunque los recursos económicos hacen imposible para la mayoría de los servicios otorgar a las clientes el tiempo y la atención que ellas reciben en el Coletivo, es importante hacer notar cuánto valoran las mujeres este servicio. Si nosotros comprendemos las prioridades de las mujeres, estaremos mejor equipados para pensar creativamente cómo responderles y argumentar más efectivamente para que sus necesidades sean consideradas por los políticos. Porque si perdemos de vista lo que las mujeres realmente quieren, podremos fácilmente perdernos a pesar de nuestros esfuerzos por mejorar la calidad del servicio.

3. Los involucrados con la investigación en planificación familiar, legislación e implementación de programas podemos obtener nuevas ideas y establecer relaciones de trabajo útiles, a partir de la comunicación y colaboración con las defensoras feministas de la salud.

4. ¡Nunca subestimes el poder del espíritu humano o tu propia imaginación! 


\section{A Nuestros Lectores}

En un principio, en Quality/Calidad/Qualité pensamos que este artículo tenía que ser escrito para aquellas mujeres alrededor del mundo que están pensando iniciar un programa alternativo, o para los profesionales establecidos de la planificación familiar que quieren comprender más acerca del movimiento internacional feminista de la salud. Finalmente, hemos tratado de tener a estas dos audiencias en mente. Nos encantaría oír tu opinión sobre este ejemplar. Háblanos de ti y de tus respuestas a la lectura sobre el Coletivo.

\section{Resumo em português}

No passado, programas de planejamento familiar eram desenhados primordialmente com o objetivo de reduzir o excesso do crescimento populacional, fazendo das mulheres objetos de políticas medicalizadas e de programas desenhados com o objetivo de regular sua fertilidade. Após a recente Conferência Internacional de População e Desenvolvimento (Cairo 1994), a necessidade de uma visão mais ampla em relaçao à saúde reprodutiva tem sido fortemente apoiada; porém, existem ainda várias questões relacionadas à implementaçao destes objetivos. Esta ediçao do Q/O/Q documenta a experiência de um grupo de mulheres brasileiras que se juntaram em busca de alternativas ao tratamento medicalizado da saúde feminina e acabaram abrindo sua própria clínica.

As memhras do Coletivo passaram anos fazendo pesquisa, conversando com mulheres a respeito de sua saúde e buscando o treinamento necessário para oferecê-las um tratamento amplo de saúde reprodutiva. Para a grande maioria das mulheres brasileiras, uma visita a um ginecol'ogista (que na maioria dos casos é um homem) é uma experiência desagradável; baseado nisto, o Coletivo decidiu treinar mulheres leigas para fornecer exames ginecológicos básicos, com a presença de uma médica na clínica. Este conceito de tratamento reconhece que as necessidades de saúde das mulheres estão intrinsecamente relacionadas com sua sexualidade, seu papel na sociedade, suas atividades econômicas e seu bem- estar emocional. Como resultado, as clientes saem da clínica com um maior reconhecimento do seu corpo o de sua sexualidade. Além do mais, o Coletivo enfatiza a prevenção e o uso de remédios naturais para diminuir a dependência da tecnologia médica e dos remédios alopáticos.

Atualmente o Coletivo tem seu próprio prédio e possui 11 membras que atendem uma média de 2500 mulheres anualmente. As atividades do Coletivo constam das seguintes: serviços clínicos, programas educacionais, treinamento, advocacia e pesquisa. Os preços dos serviços são baseados no poder aquisitivo das clientes e, considerando-se os problemas econômicos do Brasil, os lucros com estes servigos representam apenas 17 por cento do orçamento total da organização. Entretanto, como o objetivo principal do Coletivo é o de criar um modelo de assistência de saúde e não a auto-suficiência, a organização continua a depender da ajuda de doadores.

No Brasil, 85 por cento das mulheres usam a pílula anticoncepcional e a esterelização como métodos contraceptivos; outros métodos contraceptivos são praticamente inacessíveis. Este fato foi inaceitável para uma organização que se preocupa em poder oferecer opções às mulheres. Porém, oferecer outros métodos contraceptivos no Brasil também não é fácil. Sendo assim, o Coletivo teve que procurar um dos poucos lugares no país onde se oferecia treinamento para inserção do DIU. 
O Coletivo também se sentiu muito motivado em oferecer o diafragma às suas clientes. Isto porque a organização não estava somente preocupada com o grande número de mulheres tomando pílulas com contra-indicação, mas também porque queria oferecer às mulheres uma opção que 1 hes permitisse começar ou parar de usar um método quando quizessem, e que este método pudesse ao mesmo tempo oferecer alguma proteção (quando usado em conjunto com o espermicida) contra infecções. $\mathrm{O}$ argumento mais comum existente contra o diafragma é o de que toma muito tempo para ensinar o seu uso correto para as mulheres. Porém, tempo não representa uma questão para o Coletivo: a primeira consulta de uma cliente dura aproximadamente uma hora e visitas posteriores duram aproximadamente 30 minutos. Enquanto alguns programas de planejamento familiar podem considerar isto impraticável, o pessoal do Coletivo crê que este tempo dedicado às consultas é necessário para que as mulheres possam discutir suas preocupações, aprender sobre seus corpos, se tornarem cientes dos serviços oferecidos pela clínica e estabelecer um relacionamento de confiança com a profissional de saúde.

E investir no tempo compensa, pois atualmente quase 40 por cento das clientes de contraceptivos que visitam o Coletivo vão à procura do diafragma, e o Coletivo recebe também referências vindas de outras clínicas. Respondendo ao interesse crescente no método, assim como em sua filosofia centrada no cliente, o Coletivo atualmente oferece cursos para profissionais de saúde provindos de outros estados do Brasil e de outros países latino- americanos.

O Coletivo também desenvolve pesquisas que documentam o sucesso de sua filosofia. Recentemente, a organização foi escolhida dentre a outros três lugares para participar de um estudo sobre o uso do diafragma, que resultou num índice de falência de somente 6 por cento, isto é, um índice bem menor que o atribuído à pílula no Brasil. Como parte do processo de produção desta publicação, a organização também participou de um estudo de pesquisa simples que demonstrou que o investimento inicial do Coletivo no tempo é lucrativo, quando a medida deste resultado é o sucesso de um método e a satisfação da cliente.

O Coletivo Feminista Sexualidade e Saúde continua a explorar novas formas de oferecer seus serviços de maneira que as mulheres participem de sua própria saúde reprodutiva. Através de seu trabalho, elas nos mostram que isto é possível, contanto que estejamos prontas para enfrentar desafios.

\section{Résumé en Français}

Autrefois, les programmes de planification familiale avaient pour but principal de réduire la croissance excessive des populations, faisant des femmes l'objet de politiques médicalisées et de programmes destinés à réglementer leur fertilité. Suite à la récente Conférence Internationale sur la Population et le Développement (Le Caire 1994), la nécessité d'une approche plus globale concernant la santé génésique (reproductive) a été largement endorsée. Cependant nombreux sont ceux qui se demandent comment s'y prendre. Cette édition de $\mathrm{Q} / \mathrm{C} / \mathrm{Q}$ documente l'expérience d'un groupe de femmes brésiliennes qui, unies dans la recherche d'alternatives aux soins médicaux destinés aux femmes, ont fini par ouvrir leur prope clinique. 
Les membres de Colectivo ont passé des années à faire des recherches, parlant aux femmes de leur santé et recevant la formation nécessaire pour offrir à celles-ci des soins compréhensifs de santé reproductive. Pour la plupart des femmes du Brésil, une visite chez le gynécologue (presque toujours de sexe masculin), est une expérience tellement désagréable que Colectivo a décidé de former des personnes qui ne sont pas du métier, à donner, avec l'appui de femme-médicins, de simples examens médicaux.Leur approche reconnait que les besoins des femmes dans ce domaine, sont directement reliés à leur sexualité, leurs rôles sociaux, leurs activités, économiques et leur bien-être émotionnel. Ainsi, les clientes de Colectivo quittent la clinique avec une meilleure compréhension de leur corps et de leur sexualité. En outre, Colectivo met l'accent sur la prévention et l'utilisation des remédes naturels afin de réduire l'extrême dépendance sur la technologie et les drogues.

Aujourd'hui Colectivo posséde ses propres batiments et emploie 11 membres qui servent prés de 2500 femmes chaque année. En général, les activités sont divisées en cinq sections : les services cliniques, les programmes éducationnels, la formation, les plaidoiries et la recherche. Les problémes économiques du Brésil étant pris en considération, les honoraires des clients sont calculés selon leur pouvoir d'achat, et, représentent seulement 17 pourcent des revenus. Cependant, le but de Colectivo a toujours été de créer un modèle de qualité des soins et non un modèle d'auto-suffisance. Par conséquent, l'organisation continue à dépendre de l'assistance des bailleurs de fonds.

Au Brésil, les outres méthodes n'etant pratiquement pas disponibles, les contraceptifs oraux et la stérélisation représentent prés de 85 pourcent de l'ensemble des différents contraceptifs utilisés. Ceci n'était pas acceptable pour une organization qui a comme but de donner des options aux femmes. Mais offrir d'autres méthodes au Brésil n'étant pas facile, les membres ont du rechercher un ou deux endroits dans le pays où une formation en insertion des DIV était disponible.

Colectivo était également décidé à rendre le diaphragme disponible à ses clientes. Elle était non seulement concernée par le grand nombre de cas de contre-indications pour les femmes utilisant la pilule, mais elle voulait aussi offrir aux femmes une option leur permettant de commencer ou d'arrêter volontairement une méthode; méthode qui dans ce cas, pourrait offrir une protection contre les infections lorsqu'elle est utilisée avec un spermicide. L'argument généralement utilisé contre le diaphragme est que le temps pris pour former les femmes à sa bonne utilisation est trop long. Mais le temps n'est pas un probléme pour Colectivo. Les prémieres visites prennent en moyenne une heure et les visites suivantes à peu prés 30 minutes. Alors que de nombreux programmes de planification familiale considèrent ce lapse de temps peu efficace, le staff de Colectivo le croit indispensable pour que les clientes puissent explorer, de manière satisfaisante, toutes leurs préoccupations, apprendre à connaitre leur corps, découvrir les services qui leur sont disponibles et établir une relation de confiance avec les membres de la clinique.

Cet investissement en temps vaut la peine. Aujourd'hui près de 40 pourcent des clientes pour la contraception demande le diaphragme et Colectivo reçoit maintenant de nombreuses recommandations des autres cliniques. En réponse à l'intérêt accru pour cette méthode, ainsi que leur approche centrée sur la cliente, Colectivo offre maintenant plusieurs cours de formation pour les professionnels en soins de santé qui viennent d'autres régions du Brésil et de l'Amérique Latine.

Colectivo entreprend également des recherches pour documenter le succès de leur approche. Récemment,elle était un des trois sites choisi au Brésil pour participer à une étude sur l'utilisation du diaphragme, une méthode qui a un taux d'échec de seulement 6 pourcent -taux beaucoup plus bas que celui de la pilule. Comme partie intégrante au procéssus de développement de cette publication. Colectivo a également participé à de simples études de recherche qui ont démontré que son investissement initial en temps était en fait efficace au niveau coût, paticuliérement quand on le mesure en terme de l'utilisation réussie d'une méthode et de la satisfaction du client.

L'Entreprise Collective sur la Sexualité et la Santé des Femmes cotinue à être une pionnière dans les nouvelles manières d'offrir des services et d'amener les femmes à être plus responsable de leur santé. A travers son travail, elle nous montre ce qui est possible si nous sommes prêtes à relever le défi. 


\section{Sobre los Autores}

Debbie Rogow es consultora principal de organizaciones internacionales de salud reproductiva. Margarita Diaz es partera registrada que ha trabajado en investigación y capacitación en áreas de planificación familiar y salud sexual en Chile y Brasil, actualmente es jefa de la Unidad de Educación, Capacitación y Comunicación en el CEMICAMP de Brasil. José Barzelatto es Director del Programa de Salud Reproductiva y Población de la Fundación Ford, que se enfoca en los factores sociales, culturales y económicos que afectan el mejoramiento de la salud reproductiva y la sexualidad.

\section{Comité de Asesores de Quality/Calidad/Qualité}

\author{
Ian Askew \\ Karen Beattie \\ George Brown \\ Judith Bruce \\ Ethel Churchill \\ Adrienne Germain \\ Joan Haffey \\ Margaret Hempel \\ Ann Leonard \\ Magaly Marques \\ Margaret McEvoy \\ Kirsten Moore
}

\author{
Nancy Newton \\ John Paxman \\ Geeta Rao Gupta \\ Debbie Rogow \\ Jill Sheffield \\ Cynthia Steele Verme \\ Lindsay Stewart \\ Kerstin Trone \\ Nahid Toubia \\ Gilberte Vansintejan \\ Beverly Winikoff \\ Margot Zimmerman
}

Diseño:

Foto de la Portada:

Tipografía e impresión:

\author{
Ann Leonard \\ Pamela Duffy \\ mas impresos
}

Le invitamos a enviar sus comentarios e ideas sobre proyectos que pudieran ser incluídos en próximas ediciones de Quality/Calidad/Qualité. Si desea ser incluído en nuestra lista de direcciones, favor de solicitarlo a Ann Leonard, Quality/Calidad/Qualité, The Population Council, One Dag Hammarskjold Plaza, New York, N.Y. 10017, U.S.A. 


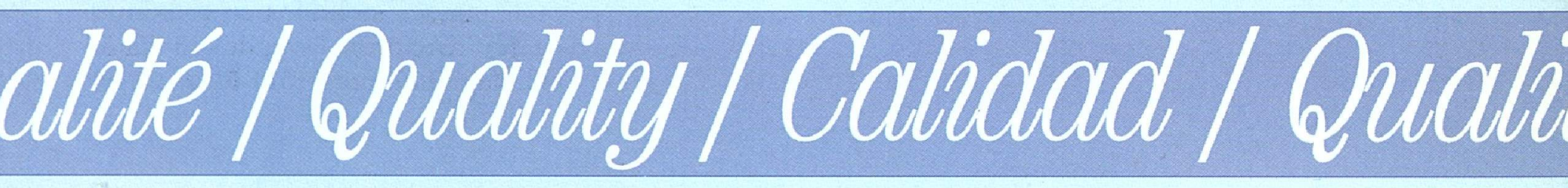

